\title{
Simulating the Cranfield Geological Carbon Sequestration Project with High-Resolution Static Models and an Accurate Equation of State
}

\author{
Mohamad Reza Soltanian', Mohammad Amin Amooie ${ }^{1}$, David R. Cole ${ }^{1}$, David E. \\ Graham $^{2}$, Seyyed Abolfazl Hosseini ${ }^{3}$, Susan Hovorka ${ }^{3}$, Susan M. Pfiffner ${ }^{4}$, Tommy \\ J. Phelps ${ }^{2}$, Joachim Moortgat ${ }^{1, *}$ \\ ${ }^{1}$ The Ohio State University, School of Earth Sciences, Columbus, OH, USA \\ 2 Oak Ridge National Laboratory, Oak Ridge, TN, USA \\ ${ }^{3}$ The University of Texas at Austin, Bureau of Economic Geology, Austin, TX, USA \\ ${ }^{4}$ The University of Tennessee, Knoxville, TN, USA
}

*Corresponding author: moortgat.1@osu.edu

\begin{abstract}
A field-scale carbon dioxide $\left(\mathrm{CO}_{2}\right)$ injection pilot project was conducted as part of the Southeast Regional Sequestration Partnership (SECARB) at Cranfield, Mississippi. We present higher-order finite element simulations of the compositional two-phase $\mathrm{CO}_{2}$-brine flow and transport during the experiment. High-resolution static models of the formation geology in the Detailed Area Study (DAS) located below the oilwater contact (brine saturated) are used to capture the impact of connected flow paths on breakthrough times in two observation wells. Phase behavior is described by the cubic-plus-association (CPA) equation of state, which takes into account the polar nature of water molecules. Parameter studies are performed to investigate the importance of Fickian diffusion, permeability heterogeneity, relative permeabilities, and capillarity. Simulation results for the pressure response in the injection well and the $\mathrm{CO}_{2}$ breakthrough times at the observation wells show good agreement with the field data. For the high injection rates and short duration of the experiment, diffusion is relatively unimportant (high Péclet numbers), while relative permeabilities have a profound impact on the pressure response. High-permeability pathways, created by fluvial deposits, strongly affect the $\mathrm{CO}_{2}$-transport and highlight the importance of properly characterizing the formation heterogeneity in future carbon sequestration projects.
\end{abstract}

\section{Introduction}

Geological $\mathrm{CO}_{2}$ sequestration (GCS) in porous formations is considered as a tool to mitigate greenhouse gas emissions into the atmosphere (e.g., Baines and Worden, 2004; Holloway, 2005; Schrag, 2007). There are different candidate reservoirs for GCS such as saline aquifers, depleted oil and gas reservoirs, and unminable coal seams (Bachu, 2000). $\mathrm{CO}_{2}$ injection in hydrocarbon reservoirs is also adopted for the purpose of enhanced oil recovery (EOR) (Dai et al., 2014a, 2016; Pan et al., 2016; Ampomah et al., 2016a,b), but saline aquifers offer the largest storage volumes in the context of GCS (DOE-NETL, 2015). 
Several field-scale pilot projects have been performed worldwide to 1) test the potential of long-term $\mathrm{CO}_{2}$ sequestration, 2) monitor the fate and transport of $\mathrm{CO}_{2}$ using various methods, and 3) evaluate the reservoir response to a large volume of $\mathrm{CO}_{2}$ injection (e.g., Arts et al., 2004; Emberley et al., 2005; Freifeld et al., 2005; Kharaka et al., 2006; Mito et al., 2008; Vasco et al., 2010; Hovorka et al., 2013; Dai et al., 2014b,c; Bacon et al., 2016). One of these pilot-projects is the large-scale pilot test that was performed near Cranfield, Mississippi, in 2009-2010. The GCS site is a brine-saturated formation down-dip of an oil field where $\mathrm{CO}_{2}$ was injected for EOR purposes by Denbury Onshore LLC (see Fig. 1). The pilot project was directed by the Southeast Regional Carbon Sequestration Partnership (SECARB), led by the Southern State Energy Board. A Detailed Area of Study (DAS) was defined that includes an injection well (F1) and two nearby observation wells (F2 and F3) in order to collect highresolution temporal evolution data. A detailed description of the project design and experimental procedures is provided by Hovorka et al. $(2011,2013)$, describing a collaboration between the University of Texas Bureau of Economic Geology (UTBEG), Sandia Technologies LLC, Oak Ridge National Laboratory (ORNL), Lawrence Berkeley National Laboratory (LBNL), U.S. Geological Survey (USGS), and the Ohio State University (OSU).

Previous studies have modeled the Cranfield pilot-project in order to match various observation datasets. Two important studies were performed by Hosseini et al. (2013) and Delshad et al. (2013). Hosseini et al. (2013) developed static and dynamic reservoir models for the formation that includes both the DAS and a commercial $\mathrm{CO}_{2}-$ EOR project at the Cranfield site. They created hundreds of high-resolution conditional realizations of facies-based static models and reduced parameter uncertainties by integrating field data. Then, using dynamic reservoir modeling and history matching, they selected the realizations that best reflected the complex flow pathways arising from subsurface heterogeneity at the site. Delshad et al. (2013) used one of those realizations to study the effect of different trapping mechanisms and hysteresis on pressure responses in the injection well and the $\mathrm{CO}_{2}$ breakthrough times in the observation wells. The DAS area is a small subsection of the computational domain in the numerical simulations by Hosseini et al. (2013) and Delshad et al. (2013). The full static models developed by Hosseini et al. (2013) contain over 60 million grid blocks and cover the entire Cranfield site, including the oil field. Therefore, to make the computational cost feasible upscaled static models were previously adopted to represent the spatial variability in permeability and porosity. The Cranfield pilot test has also been modeled in the Sim-SEQ project using different reservoir simulators (e.g., TOUGH2/EOS7C, STOMP-CO2e, TOUGH2-MP/ECO2N, VESA, MoReS; see Mukhopadhyay et al., 2012, 2015). In Sim-SEQ, each group developed their own conceptual reservoir characterization, with the DAS represented by a small number of grid cells in an upscaled site-scale static model.

Many candidate reservoirs for GCS and commercial $\mathrm{CO}_{2}$-EOR have sedimentary architectures reflecting fluvial deposition (McGuire and Stalkup, 1995; McGuire et al., 1995; Gershenzon et al., 2015a; Lu et al., 2012a). The target formation near Cranfield, 
located in the lower Tuscaloosa formation, is comprised of fluvial deposits of considerable heterogeneity (Hovorka et al., 2011, 2013). 3D seismic surveys and core samples have revealed this complex heterogeneity with multiple laterally discontinuous 3D sand bodies (facies) (see Figure 3 in Lu et al., 2012a). Hosseini et al. (2013) employed an object-modeling approach by embedding geobodies in order to create high-resolution static models that conform to these observations. The objective of this work is to take advantage of the full detail in these models, i.e. without upscaling, to study how the fluvial architecture at the site (e.g., channels and their connectivity) controls fluid flow and $\mathrm{CO}_{2}$ transport within the DAS during the injection experiment. Developing such predictive models of $\mathrm{CO}_{2}$ transport is critical for 1) estimating residence time, reservoir storage capacity, and storage mechanisms, 2) testing injection scenarios for process optimization, and 3) assessing potential leakage of $\mathrm{CO}_{2}$ from the reservoir utilizing long-term monitoring techniques.

Reservoir modeling of $\mathrm{CO}_{2}$ injection in saline formations relies on the parameterization of certain core-scale processes measured in laboratory experiments. The relative permeabilities of brine and $\mathrm{CO}_{2}$ are key parameters. We use the measured relative permeabilities reported in Hosseini et al. (2013), and used by Delshad et al. (2013). We also perform parameter studies to determine the sensitivity of $\mathrm{CO}_{2}$ breakthrough times and pressure responses to different relative permeability parameters such as the residual water saturation, curvature exponents for $\mathrm{CO}_{2}$ and brine, and $\mathrm{CO}_{2}$ end-point relative permeability. The influence of capillarity and Fickian diffusion are investigated as well. Without diffusion, injected $\mathrm{CO}_{2}$ tends to flow primarily through high-permeable pathways, but compositional gradients between different facies with high and low permeability can drive considerable cross-flow behavior (Moortgat and Firoozabadi, 2013, 2016; Moortgat, 2016).

The paper is organized as follows: in Section 2 we briefly describe the Cranfield site with a specific focus on the DAS area. Section 3 presents the governing equations in our simulator, and Section 4 is devoted to a description of the numerical methods used in this study. Section 5 describes the Cranfield static model developed by Hosseini et al. (2013). The set-up of the 3D CO 2 injection simulations is presented in Section 6. Section 7 discusses the results of our numerical simulations with further sensitivity analyses in Sections 8-11. Finally, Section 12 highlights the main conclusions of this work. 


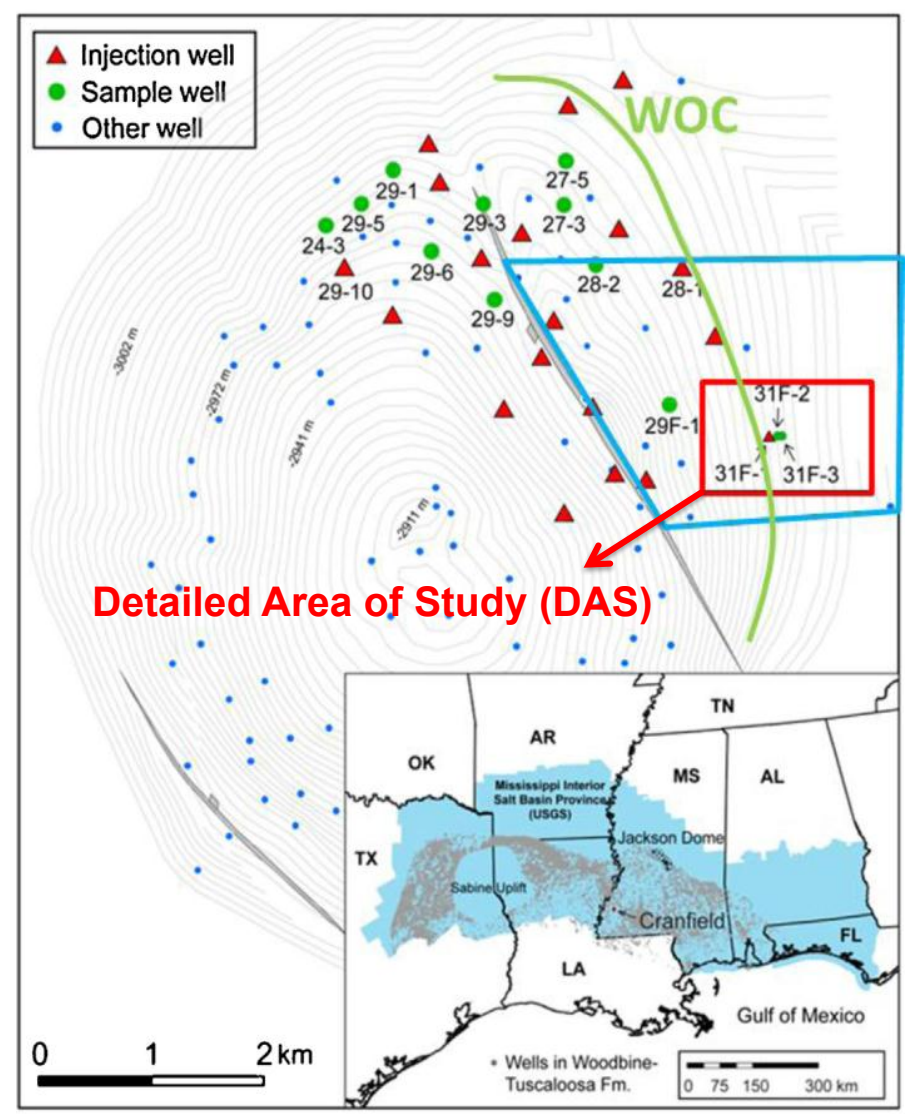

Fig.1. Map of the Cranfield site (modified from Hosseini et al., 2013). The DAS area is part of a larger domain called the high volume injection test area (HiVIT), shown by the blue trapezoid. The DAS is shown by the red box with wells F1, F2, and F3 located down-dip of the oil field (locations of other wells in the field are also shown). A major sealing fault (grey line) to the northeast separates the field into east and west sections. The wells in DAS are located below the water-oil contact (WOC) where only injected $\mathrm{CO}_{2}$ and brine exist.

\section{Description of Cranfield site}

The Cranfield site is located about $20 \mathrm{~km}$ east of Natchez in southwestern Mississippi, U.S.A. (see Fig.1). The oil reservoir in Cranfield was discovered in 1943 and oil production was continued until 1966 (Weaver and Anderson, 1966). An EOR $\mathrm{CO}_{2}$ injection project began in 2008. The target formation for the pilot project at the DAS area consists of fluvial sandstones of the Cretaceous lower Tuscaloosa Formation at depths of 3,300 m. A more detailed description of the geology can be found in Hovorka et al. $(2011,2013)$.

The DAS is located in the water leg of the reservoir with close proximity the $\mathrm{CO}_{2}$ EOR wells (see Fig. 1). The target formation was initially saturated with brine. The DAS has three wells. For the pilot test, $\mathrm{CO}_{2}$ was injected through an injection well (F1), and was monitored by two observation wells (F2 and F3). Wells F2 and F3 were perforated through the same sand intervals and they are lined up approximately with F1 with distances of about $68 \mathrm{~m}$ and $112 \mathrm{~m}$ to the east, respectively (more on the well locations below). During the highly integrated pilot project, different types of data were acquired 
such as extensive down-hole and surface geophysical and geochemical data. Different monitoring techniques were also evaluated in order to improve understanding of $\mathrm{CO}_{2}$ behavior (Lu et al., 2012a,b). The $\mathrm{CO}_{2}$ injection pilot project started on December $1^{\text {st }}$ in 2009 with an initial injection rate of $\sim 175 \mathrm{~kg} / \mathrm{min}$. After about 20 days, the rate was increased to $\sim 300 \mathrm{~kg} / \mathrm{min}$, and after 156 days the rate was raised again to $500 \mathrm{~kg} / \mathrm{min}$. The focus of this work is on the pressure response and the $\mathrm{CO}_{2}$ breakthrough times at the observation wells in the first 230 days of $\mathrm{CO}_{2}$ injection. The field-schedule injection rates and observed pressure responses are taken from Hosseini et al. (2013). The observed breakthrough times of 11 days for F2 and 16 days for F3 are from Hovorka et al. (2013).

\section{Governing equations}

In this section, we briefly summarize the equations that govern our simulations.

\subsection{Species transport equation}

The molar balance equations are given by:

$\phi \frac{\partial c z_{i}}{\partial t}+\nabla \cdot \vec{U}_{i}=F_{i}, \quad i=1,2$

where is porosity, $c\left[\mathrm{~mol} / \mathrm{m}^{3}\right]$ is the overall molar density; $z_{i}$ is the overall mole fraction of component $i$ ( 1 is brine and 2 is $\mathrm{CO}_{2}$ ) with $z_{i}=1, t[\mathrm{~s}]$ is time, $\vec{U}_{i}\left[\mathrm{~mol} / \mathrm{m}^{2} / \mathrm{sec}\right]$ is total molar flux of component $i$, and $F_{i}\left[\mathrm{~mol} / \mathrm{m}^{3} / \mathrm{s}\right]$ is a source term of component $i$. The $\vec{U}_{i}$ is the sum of diffusive $\left(J_{i}\right)$ and convective phase fluxes:

$$
\begin{aligned}
& \overrightarrow{U_{i}}=\sum_{\alpha}\left(c_{\alpha} x_{\alpha i} v_{\alpha}+S_{\alpha} J_{\alpha i}\right), \quad i=1,2, \quad \alpha=w, g \\
& J_{\alpha 2}=c_{\alpha} \phi D \nabla x_{\alpha 2}, \quad J_{\alpha 1}=-J_{\alpha 2}
\end{aligned}
$$

where the subscript denotes the brine phase $(w)$ and $\mathrm{CO}_{2}$ gas phase $(g), c$ is phase molar density, $x_{i}$ is the mole fraction of component $i$ in phase $\quad\left(x_{1}+x_{2}=1\right), v[\mathrm{~m} / \mathrm{s}]$ is the phase fiducial velocity, $S$ is the phase saturation, $J_{i}$ is the diffusive flux of component $i$ in phase, and $D$ [m²/sec] is the diffusion coefficient of $\mathrm{CO}_{2}$ in brine. Note that we neglect water vaporization, so diffusion only occurs within the aqueous phase $\left(J_{g i}=0\right)$.

\subsection{Darcy's law and pressure equation}

In order to find the phase velocity, Darcy's law is invoked as:

$v=\underline{K}(\nabla p \quad g)$ 
where $p[\mathrm{~Pa}]$ is the phase pressure. The phase pressures are related by the capillary pressure between brine and gas $\left(p_{c, g w}=p_{g} \quad p_{w}\right)$, which is a function of water saturation. $g\left[\mathrm{~m} / \mathrm{s}^{2}\right]$ is the gravitational acceleration, $\underline{K}\left[\mathrm{~m}^{2}\right]$ is the permeability tensor, $[\mathrm{m} . \mathrm{s} / \mathrm{kg}]$ is the phase mobility, calculated from the phase saturation $S$, relative permeability $\left(k_{r}\right)$ and phase viscosity $([\mathrm{kg} / \mathrm{m} / \mathrm{s}])$, as $(S)=k_{r} /$. The mass density of phase , $\left[\mathrm{kg} / \mathrm{m}^{3}\right]$, is related to the molar density as:

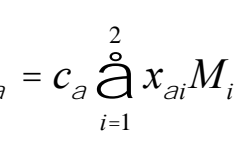

where $M_{i}[\mathrm{~g} / \mathrm{mol}]$ is the molecular weight of the brine and $\mathrm{CO}_{2}$ components. Instead of solving for each phase velocity individually, we adopt the fractional flow formulation in terms of a total velocity (Hoteit and Firoozabadi; 2006, Moortgat et al., 2011; Pope, 1980; Binning and Celia, 1999).

We use the concept of volume-balance by Acs et al. (1985), which leads to the following pressure equation:

$\phi C_{f} \frac{\partial p}{\partial t}+\sum_{i=1}^{2} \bar{v}_{i} \nabla \cdot \vec{U}_{i}=\sum_{1}^{2} \bar{v}_{i} F_{i}, \quad i=1,2$

where $C_{f}\left[\mathrm{~m} . \mathrm{s}^{2} / \mathrm{kg}\right]$ is the total compressibility, $\bar{v}_{i}\left[\mathrm{~m}^{3} / \mathrm{mol}\right]$ is the total partial molar volume of component $i$. The $C_{f}$ and $\bar{v}_{i}$ are calculated following Firoozabadi (2015) (see also Moortgat et al., 2011).

\subsection{Two-phase relative permeabilities}

Relative permeability is a rock-fluid property and represents the fractional reduction in fluid conductivity due to the diversion of fluid flow pathways by the presence of other fluid phases. Relative permeability values are between 0 and 1 and are a strong function of phase saturations (Stone 1970, 1973; Delshad and Pope, 1989; Lake, 2010). The relative permeability model used in this work is a variation of Brooks-Corey type relations (Brooks and Corey, 1964). The brine and gas relative permeabilities $\left(k_{r w}, k_{r g}\right)$ are determined by:

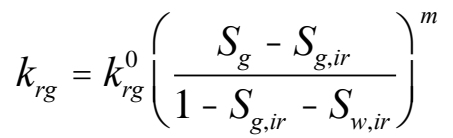

$$
\begin{aligned}
& k_{r w}=k_{r w}^{0}\left(\frac{S_{w}}{S_{w, i r}} S_{w, i r} S^{n}\right)^{n}
\end{aligned}
$$

where $k_{r g}^{0}$ and $k_{r w}^{0}$ are the brine and $\mathrm{CO}_{2}$ end-point relative permeabilities, $S_{w, i r}$ and $S_{g, i r}$ 
are the residual or irreducible saturation of brine and $\mathrm{CO}_{2}, m$ and $n$ are the curvature exponents of gaseous $\mathrm{CO}_{2}$ and brine, respectively.

In Section 8, we perform sensitivity simulations to $k_{r g}^{0}, S_{w, i r}, m$, and $n$. The Cranfield pilot project addressed only the drainage phase (continuous injection of supercritical $\mathrm{CO}_{2}$ for over 200 days); therefore, $k_{r w}^{0}$ and $S_{g, i r}$ are 1 and 0 , respectively (as in Hosseini et al., 2013 and Delshad et al., 2013).

\section{Description of reservoir simulator}

The physical and chemical processes controlling the transport of $\mathrm{CO}_{2}$ in GCS sites are quite complex, due to, e.g., $\mathrm{CO}_{2}$ phase behavior and different types of trapping mechanisms (e.g., residual, solubility, structural, and mineral). We utilized numerical methods presented in earlier work (Moortgat and Firoozabadi, 2010, 2013, 2016 a,b; Moortgat et al., 2011, 2012, 2013; Shahraeeni et al., 2015). Specifically, we adopt a second-order discontinuous Galerkin (DG) method for the transport equations, which has low numerical dispersion. A Mixed Hybrid Finite Element (MHFE) method is used to solve the Darcy and pressure equations simultaneously, which provides accurate velocity and pressure fields. These methods were developed specifically to obtain more accurate results in highly heterogeneous media, such as fractured and layered formations (Hoteit and Firoozabadi, 2006). MHFE is useful for the simulations in this work due to sharp contrasts in the heterogeneous permeability fields arising from spatial organization of facies in our static models. The flow and transport problems are coupled by the common IMplicit-Pressure-Explicit-Composition (IMPEC) scheme.

Thermodynamic equilibrium is satisfied by requiring the equality of the fugacities of components in each phase. The calculation of the phase fugacities, phase compositions, molar fractions of each phase, total fluid compressibility, and the total partial molar volume are based on the cubic-plus-association (CPA) equation-of-state (EOS). The CPA-EOS was developed to model the phase behavior of fluids that contain polar molecules, such as water (Firoozabadi, 2015). CPA-EOS takes into account the self-association between water molecules, as well as the (polar-induced) crossassociation between water and $\mathrm{CO}_{2}$ (Li and Firoozabadi, 2009, 2012; Moortgat et al., 2012). Phase split computations based on an EOS are an improvement over empirical correlations, such as Henry's law, and strictly enforce local thermodynamic equilibrium.

\section{Description of the Cranfield static model}

Reservoir heterogeneity has important effects on fluid flow and mass transport. It can be quite pronounced in formations created by fluvial depositions, which are important target reservoirs for $\mathrm{CO}_{2}$ sequestration. Well known examples include the lower Mt. Simon Sandstone (Freiburg et al., 2014; Ritzi et al., 2016); the lower Paaratte Formation (Krevor et al., 2012; Dance and Patterson, 2016); the Victor interval of the Ivishak Formation (Tye et al., 2003; Gershenzon et al., 2014, 2015b); the Morrow Sandstone (Dai et al., 2016; Gallagher, 2014); and the lower Tuscaloosa Formation (Krevor et al., 2012; Lu et al., 2012a,b). Fluvial formations exhibit subsurface heterogeneities that are characterized by the spatial organization of multiple facies 
types with multiple laterally discontinuous sand facies. This complexity results in variable connectivity and flow pathways arising from the patterns of point-bars and channels (e.g., Sneider et al., 1978; Willis and White, 2000; Snedden et al., 2007; Deveugle et al., 2011; Lu et al., 2012a,b). The nature of fluvial deposits can exert strong control on $\mathrm{CO}_{2}$ dynamics because of high variability in petrophysical properties (e.g., permeability and porosity; Gershenzon et al., 2015a; Ritzi et al., 2016).

Extensive studies were performed by the UTBEG research team to characterize the nature of the fluvial deposits observed at the Cranfield site and to realistically represent the subsurface heterogeneity. We use the history-matched static petrophysical reservoir models developed by Hosseini et al. (2013). This is the best data available for the Cranfield site. Briefly, the top and bottom of the 3D static models were determined by a 3D seismic survey and are modeled as impermeable layers. Conditional realizations of facies types were created by geostatistical simulations using an object-modeling approach (see Fig.10 in Hosseini et al., 2013). There are 8 different operational facies in the model domain: 4 lower permeability facies groups (clay-rich) and 4 higher permeability facies groups (sandstones). Each was given uniform permeability and porosity values. In these static models, sands and channels have sinusoidal shapes with variable wavelength, amplitude, thickness, and width corresponding to the observed fluvial architecture. Subsequently, the partitioning of each facies and the measured facies permeability and porosity values were assigned based on well log locations. Three facies-based static models were created and used to generate hundreds of conditional realizations with different petrophysical properties. History matching was performed using dynamic data (e.g., pressure response, and $\mathrm{CO}_{2}$ breakthrough times) to pick the best realizations. The resulting static reservoir models have a high-resolution with grid block size of $3.048 \mathrm{~m}(10 \mathrm{ft}) \times 3.048 \mathrm{~m}(10 \mathrm{ft}) \times$ by $0.3048 \mathrm{~m}(1 \mathrm{ft})$ in the $x, y$, and $z$ directions, respectively, requiring more than 60 million grid blocks. Therefore, Hosseini et al. (2013) used upscaled static models in a commercial simulator (CMG-GEM) and compared the simulation results with fieldmeasured $\mathrm{CO}_{2}$ breakthrough times in $\mathrm{F} 2$ and $\mathrm{F} 3$, along with bottom-hole pressure in $\mathrm{F} 1$. Delshad et al. (2013) also used volume-weighted arithmetic averaging and directional arithmetic-harmonic averaging to upscale porosity and permeability, respectively. In these studies the DAS area was represented by a relatively small number of grid blocks in the computational domain.

In this work, we use the high-resolution static models without upscaling. This allows us to more accurately model the effects on pressure response and $\mathrm{CO}_{2}$ dynamics of small-scale variability in petrophysical properties that arise from the spatial organization of facies. In order to make the numerical simulation computationally feasible we extract only the DAS to reduce the number of grid cells. Our computational domain includes the full $24 \mathrm{~m}$ thickness of the target formation and has 257,856 unstructured grid blocks that conform to the formation geometry (see Fig. 2). Fig. 3 and Fig. 4 show the permeability and porosity, respectively, for the best history-matched realization from Hosseini et al.(2013) throughout the grid in both 3D and on a few 2D cross-sections. We refer to this realization of heterogeneity as the Base-Case throughout this article. 


\section{Modeling approach}

We model the transport of brine- $\mathrm{CO}_{2}$ with our in-house reservoir simulator, Osures, discussed in Section 4. We only consider brine and $\mathrm{CO}_{2}$ components. The CPA-EOS parameters are tuned to match the fluid properties observed at the Cranfield site (see Table 1). Specifically, the brine density and viscosity are $1,039 \mathrm{~kg} / \mathrm{m}^{3}$, and $0.22 \mathrm{cp}$, respectively. Note that the brine density is higher than that of pure water. The $\mathrm{CO}_{2}$ density and viscosity are $578 \mathrm{~kg} / \mathrm{m}^{3}$, and $0.022 \mathrm{cp}$, respectively. Our density and viscosity values are close to the calculated values by Delshad et al. (2013). The above values are in line with those in the NIST chemistry webbook (Lemmon et al., 2005) for pure $\mathrm{CO}_{2}$ and pure water at the aquifer temperature and pressure (given below).

As shown in Fig. 2, we use non-orthogonal hexahedral grid elements to discretize a physical domain of $155 \mathrm{~m}$ by $195 \mathrm{~m}$ and $24 \mathrm{~m}$ in the $x, y$, and $z$ directions, respectively, to cover the DAS area. The number of grid cells in $x, y$, and $z$ directions are 64,51 , and 79 . The grid includes the perforated injection well (F1) on one boundary and the two non-intrusive/non-interacting observation wells (F2 and F3) inside the computational domain. The initial conditions for $\mathrm{CO}_{2}$ injection consist of a brinesaturated formation at constant temperature $\left(128{ }^{\circ} \mathrm{C}\right)$ and hydrostatic pressure (initially $32 \mathrm{MPa}$ at the bottom). The initial pressure and temperature are taken from the observed pre-injection values in the injection well (F1) reported in Delshad et al. (2013) and Hosseini et al. (2013). The relative permeability curves for the formation are BrooksCorey type (Eq.(5) and Eq.(6)) with parameter values listed in Table 2. The boundaries away from the injection well are kept at constant-pressure (open). The top and bottom boundaries are impermeable (no-flow). Sensitivity studies of the effect of capillarity scale the capillary pressure by the Leverett $J$-function (Leverett, 1941) to account for spatial variability in permeability and porosity.

Table 1

EOS parameters.

\begin{tabular}{lll}
\hline $\mathrm{P}=32 \mathrm{MPa}, \mathrm{T}=128^{\circ} \mathrm{C}$ & $\mathrm{CO}_{2}$ & Brine \\
\hline Critical temperature $\left({ }^{\circ} \mathrm{C}\right)$ & 30.85 & 373.85 \\
Critical pressure $(\mathrm{MPa})$ & 7 & 22 \\
Acentric factor & 0.24 & 0.22 \\
Molecular weight $(\mathrm{g} / \mathrm{mole})$ & 44 & 18 \\
Volume-shift parameter & 0 & 0.3 \\
Binary interaction coefficient & 0.28 & 0.28 \\
\hline
\end{tabular}


Table 2

Brooks-Corey type parameters for relative permeability drainage curves (from Delshad et al., 2013) in our Base-Case simulation.

\begin{tabular}{cc}
\hline Parameters & Values \\
\hline$S_{w, i r}$ & 0.4 \\
$S_{g, i r}$ & 0.0 \\
$k_{r w}^{0}$ & 1.0 \\
$k_{r g}^{0}$ & 0.8 \\
Gaseous $\mathrm{CO}_{2}$ exponent $(m)$ & 2.6 \\
Brine exponent $(n)$ & 4.2 \\
\hline
\end{tabular}

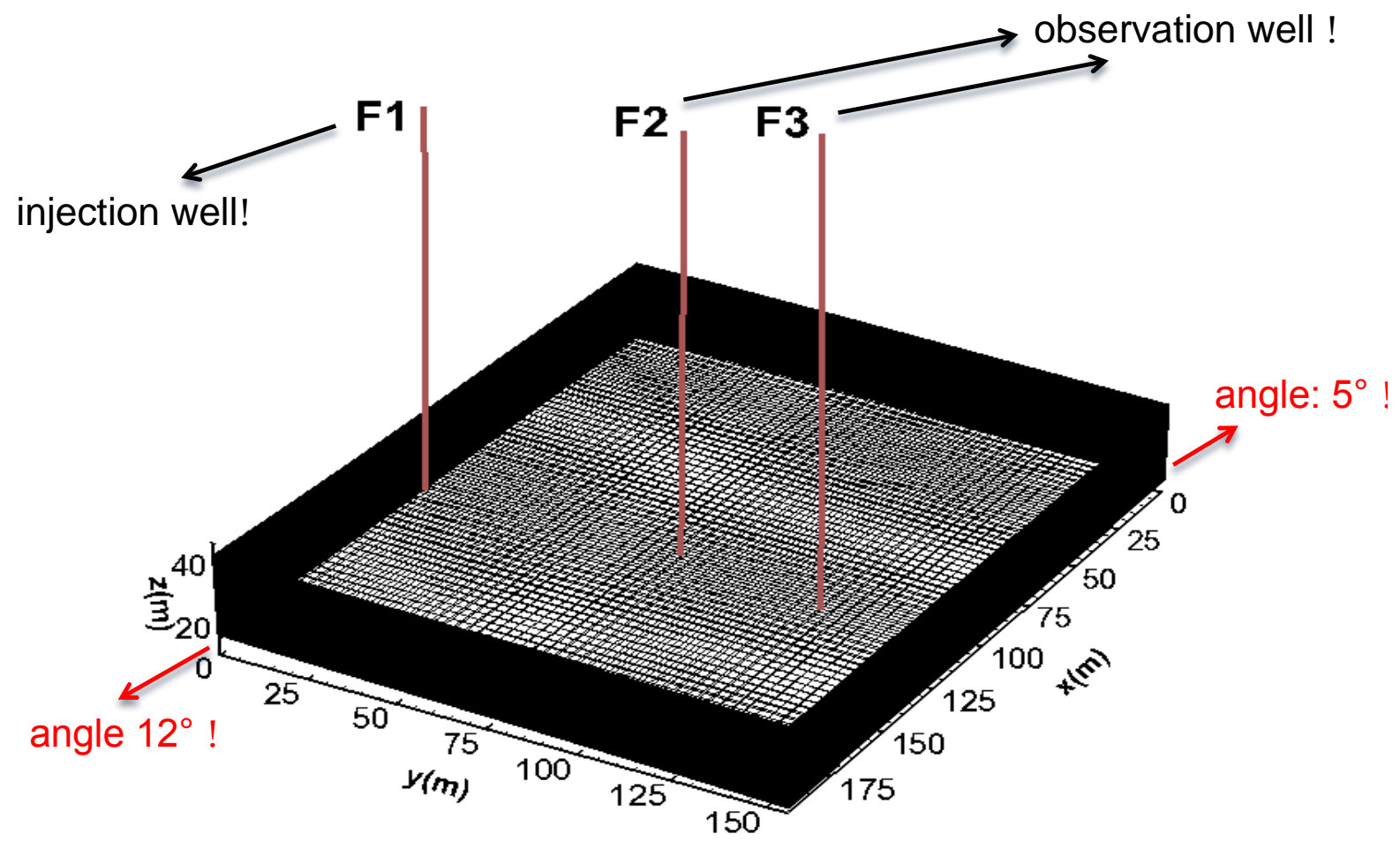

Fig. 2. Numerical grid for the Cranfield Detailed Area of Study (DAS). The grid is $155 \times 195 \times$ $24 \mathrm{~m}^{3}$, with 257,856 hexahedral elements. The injection well F1 and observation wells $\mathrm{F} 2$ and F3 are shown by the red straight lines, at $68 \mathrm{~m}$ and $112 \mathrm{~m}$ from $\mathrm{F} 1$, respectively. The domain is inclined in both the $x$ and $y$ directions. 

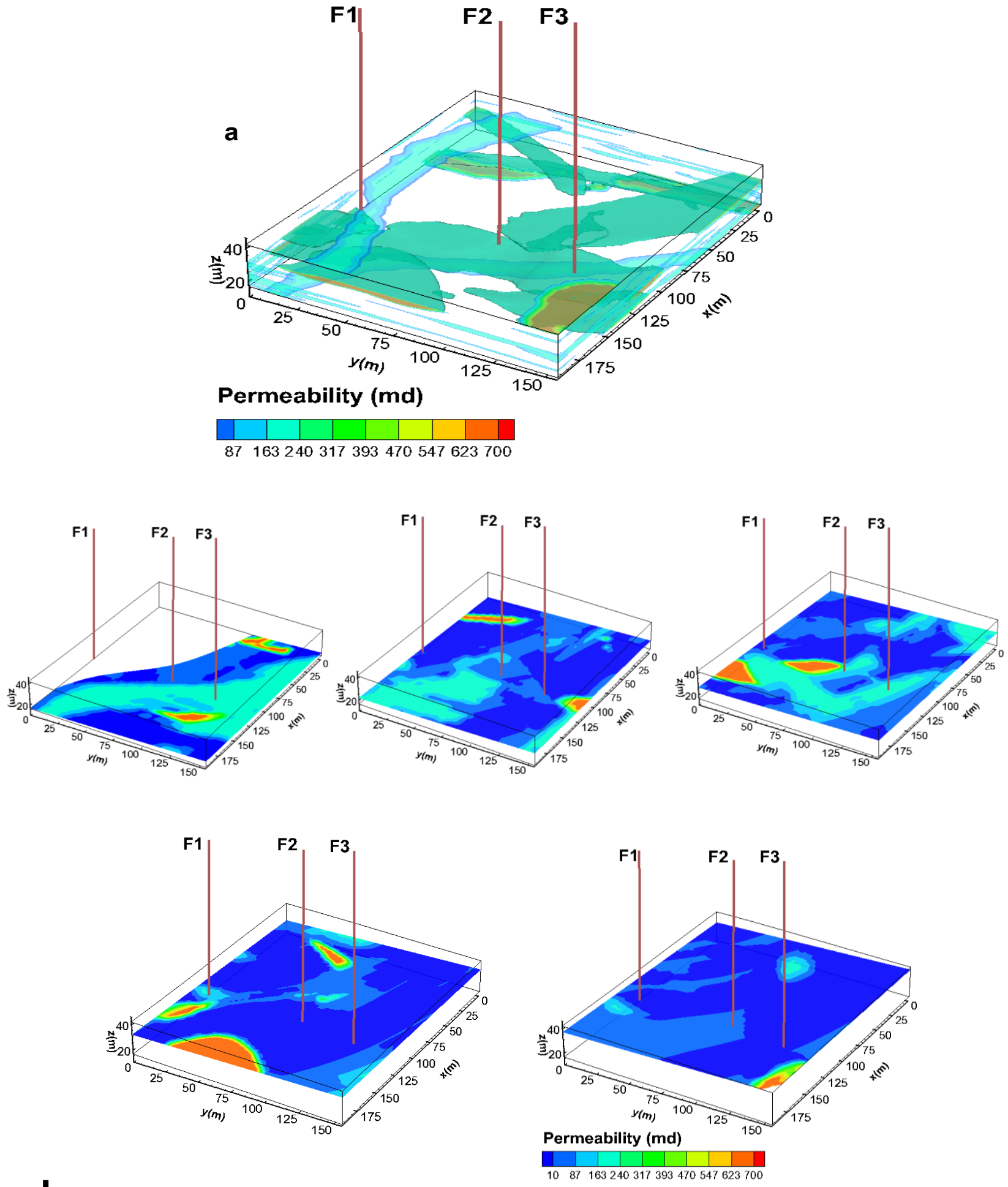

b

Fig.3. (color online) Formation permeability shown (a) as contours throughout full DAS in 3D, (b) on five 2D horizontal cross-sections (red straight lines showing the location of the injection well, F1, and two observation wells, F2 and F3). The geometry of modeled fluvial channels is clear and it is consistent with the fluvial interpretation of the site (see Hosseini et al., 2013) 


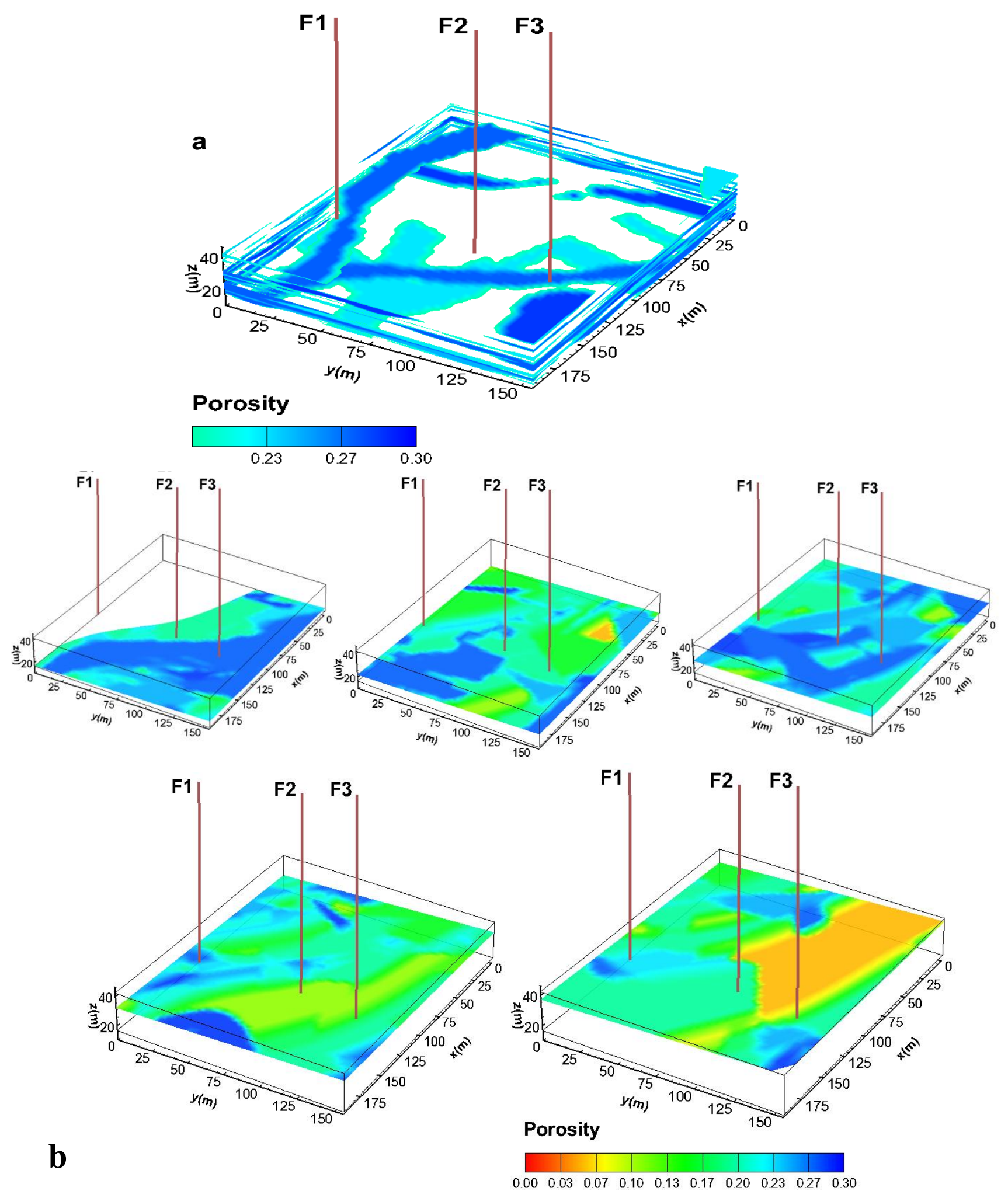

Fig. 4. (color online) Formation porosity shown (a) as contours throughout full DAS in 3D, (b) on five 2D horizontal cross-sections (red straight lines showing the location of the injection well, $\mathrm{F} 1$, and the two observation wells, F2 and F3). 


\section{Comparison between observed data and numerical simulations}

\subsection{Bottom-hole pressure in injection well F1}

Fig. 5 shows the field-schedule injection rates provided by UTBEG and published in Hosseini et al. (2013) as well as the injection rate schedule used in our simulations. Fig. 6 compares the bottom-hole pressure (BHP) in the injection well (F1) as measured in the field and for our Base Case simulation.

It is clear from Fig. 6 that we are able to match the BHP in the injection well reasonably well up to 157 days, corresponding to the time that the injection was increased to the highest rate of about $500 \mathrm{~kg} / \mathrm{min}$. Overall our simulated pressure evolution in the DAS also agrees well with previous studies that modeled the entire Cranfield site (Delshad et al., 2013; Hosseini et al., 2013; Mukhopadhyay et al., 2012, 2015). After 157 days, the field data indicate that the pressure response was relatively insensitive to a rate increase of $\sim 40 \%$, while simulations show a considerable pressure jump. The discrepancy between measured and simulated pressures for this highest rate is less than in some prior studies, which could be due to 1) the high-resolution (notupscaled) static model in our simulations, and 2) the use of MHFEM to simultaneously solve for accurate pressures and fluxes in a heterogeneous medium. Delshad et al. (2013) and Hosseini et al. (2013) argued that the formation might have been fractured during this highest $\mathrm{CO}_{2}$ injection rate and showed that a better match between measured and simulated pressures could be obtained by artificially adding high permeability grid cells (mimicking a fracture) from the injection well to the observation well (and in the opposite direction). While fracture formation is possible, we also believe that this could be a realization-dependent phenomenon. To investigate the sensitivity of the pressure response to the permeability field, we perform high-resolution simulations for two more of the best history-matched static models developed by UTBEG (Static Model 2 and Static Model 3). The main difference between the static models is the spatial distribution of geobodies (facies). The results in Fig. 7 show that 1) the pressure response is quite sensitive to the spatial distribution of facies types, and 2) the BaseCase static model, while not perfect, shows the best match to the field data. The sensitivity of the pressure response to other rock and fluid properties will be investigated below.

Cranfield core samples reveal multiple upward-fining intervals from conglomerate to fine sandstones, dominated by low-angle cross-bedding (see Lu et al., 2012a). This corresponds to conglomerates deposited as lateral migration of channels (see Bridge, 2009). Our simulation results confirm the importance of these channels for $\mathrm{CO}_{2}$ migration (see Fig. 8 and Supplementary material). Fig. 8 shows a yellow contour of the $\mathrm{CO}_{2}$ front (a molar fraction or 0.001 ) with superimposed contours of the permeability field after 10, 15, 20, and 25 days of injection in the Base-Case simulation. The influence of higher permeable channel features (flow channeling) on the evolution of $\mathrm{CO}_{2}$ is clear. The animations provided in the Supplementary material better show the influence of formation heterogeneity and channeling on the transport of $\mathrm{CO}_{2}$. The channels have higher permeability and porosity than clay-rich facies and their spatial 
organization and connectivity are important controls on the $\mathrm{CO}_{2}$ migration.

The volume fraction and connectivity of high permeability facies are among the biggest uncertainties in flow and transport models (Lu et al., 2012a). To show the importance of the channel features (Facies $S$ hereafter) we increased their permeability from our Base-Case simulation systematically by factor of 2, 5, and 10 to investigate how the channel permeability affects the pressure. The results are shown in Fig.9. It is clear that permeability in channel features has a large effect on the pressure response.

Another important factor to consider is that in the UTBEG static models constant values of permeability and porosity are assigned to each facies. These values are determined by a geological interpretation of core samples and their range of permeability and porosity. However, it is possible that internal heterogeneity within each facies (facies types at smaller scales) also affect the pressure response. Permeability measurements in core plugs (see Fig. 2 in Lu et al., 2012a) for F2 and F3 show that the fluvial channel facies (see Fig. 3 and Fig. 4) could have permeabilities up to $1500 \mathrm{md}$, while the averaged permeability in the UTBEG representation of this facies is $\sim 170 \mathrm{md}$. Future work could investigate the effects of internal heterogeneity within channel features. Incorporating small-scale variability or internal heterogeneity in numerical simulations could be computationally expensive due to the large number of voxels required to represent the small-scale facies architecture (see Gershenzon et al., 2014, 2015a,b).

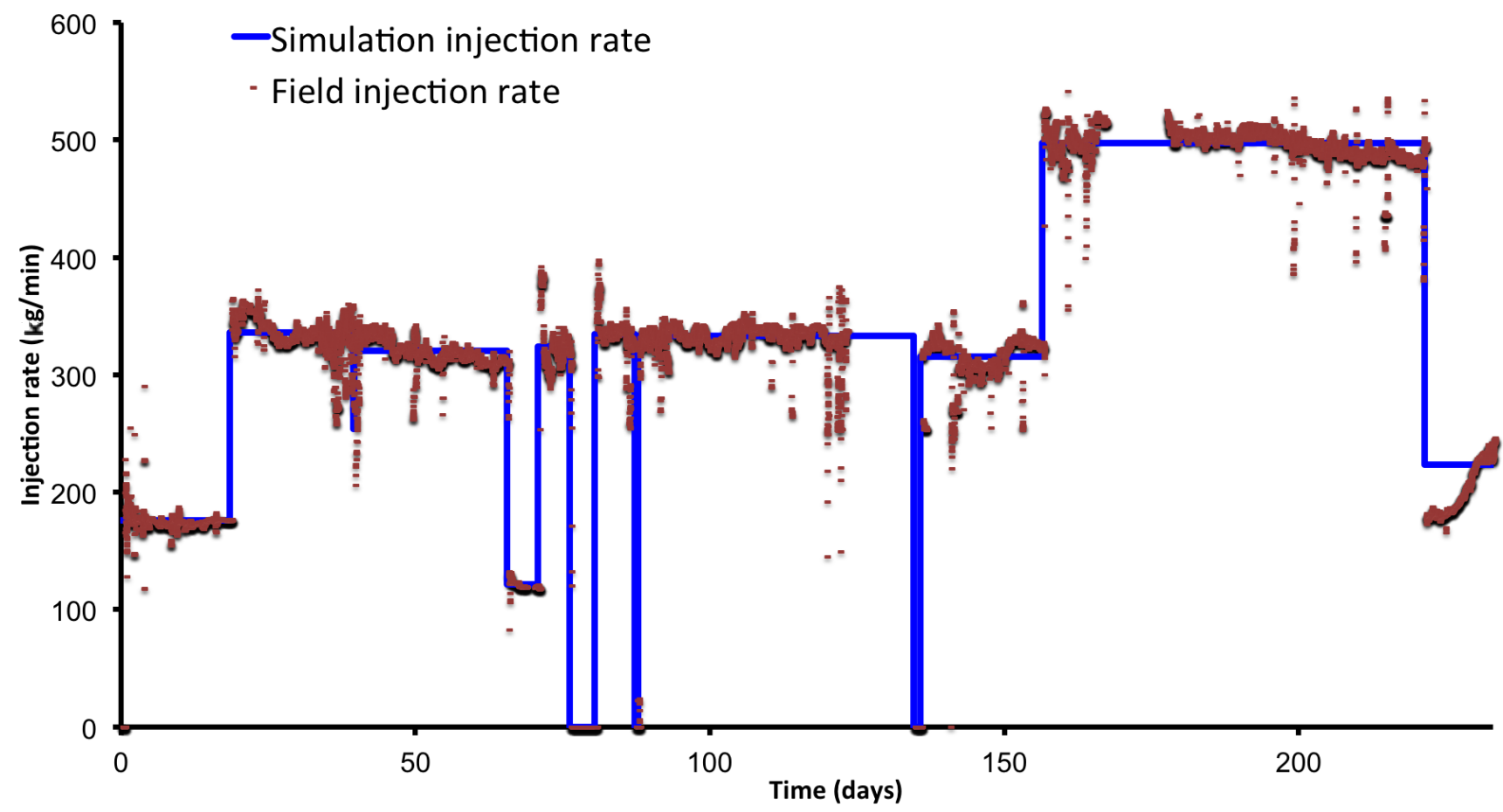

Fig. 5. (color online) Field-schedule injection rates (red dots) published in Hosseini et al. (2013) and the injection rate schedule used in our simulations. 


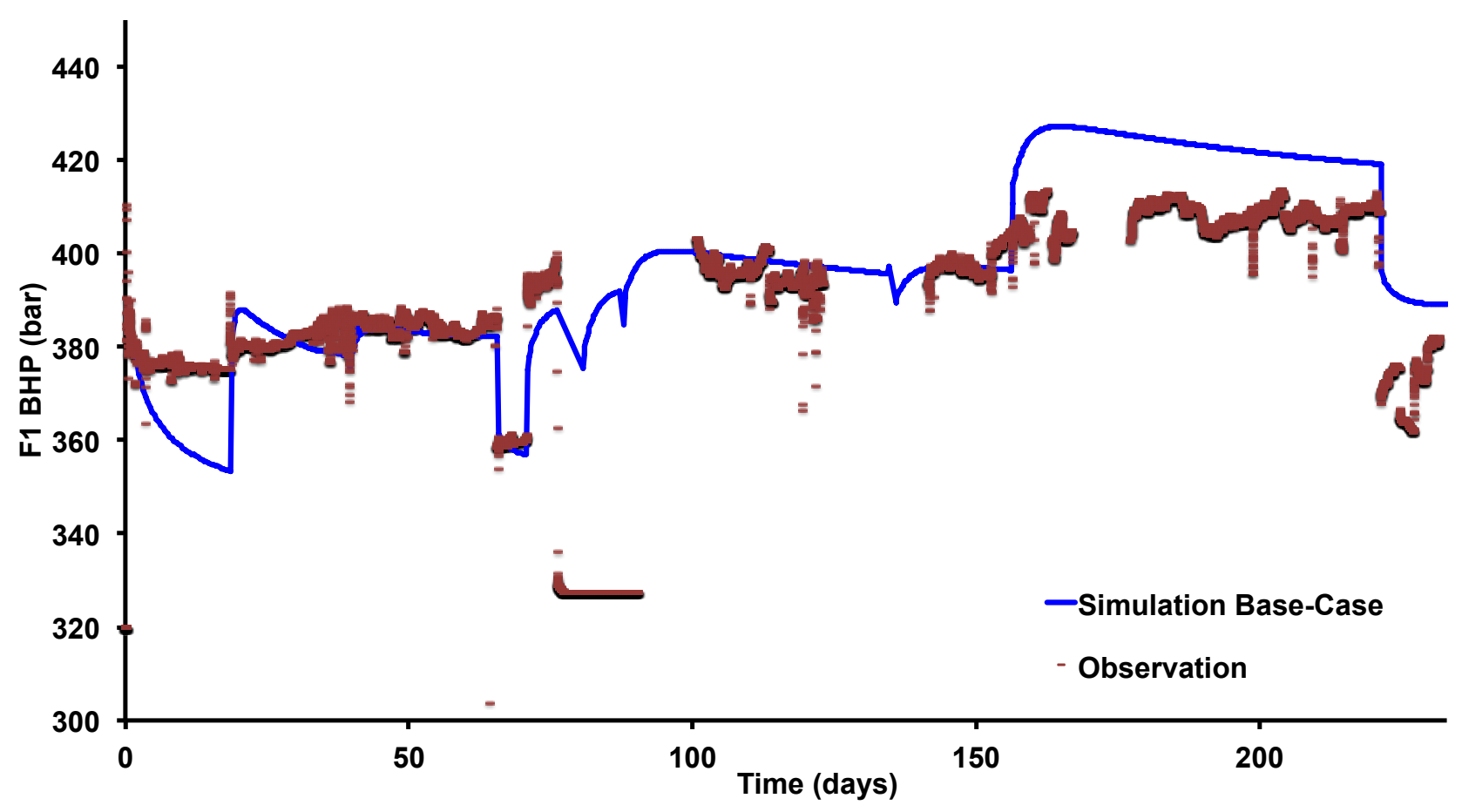

Fig.6. (color online) Observed (red dots) and simulated BHP in F1 for the 230 days duration of Cranfield pilot test. Day 0 is on December 1, 2009 and day 230 is July 22, 2010.

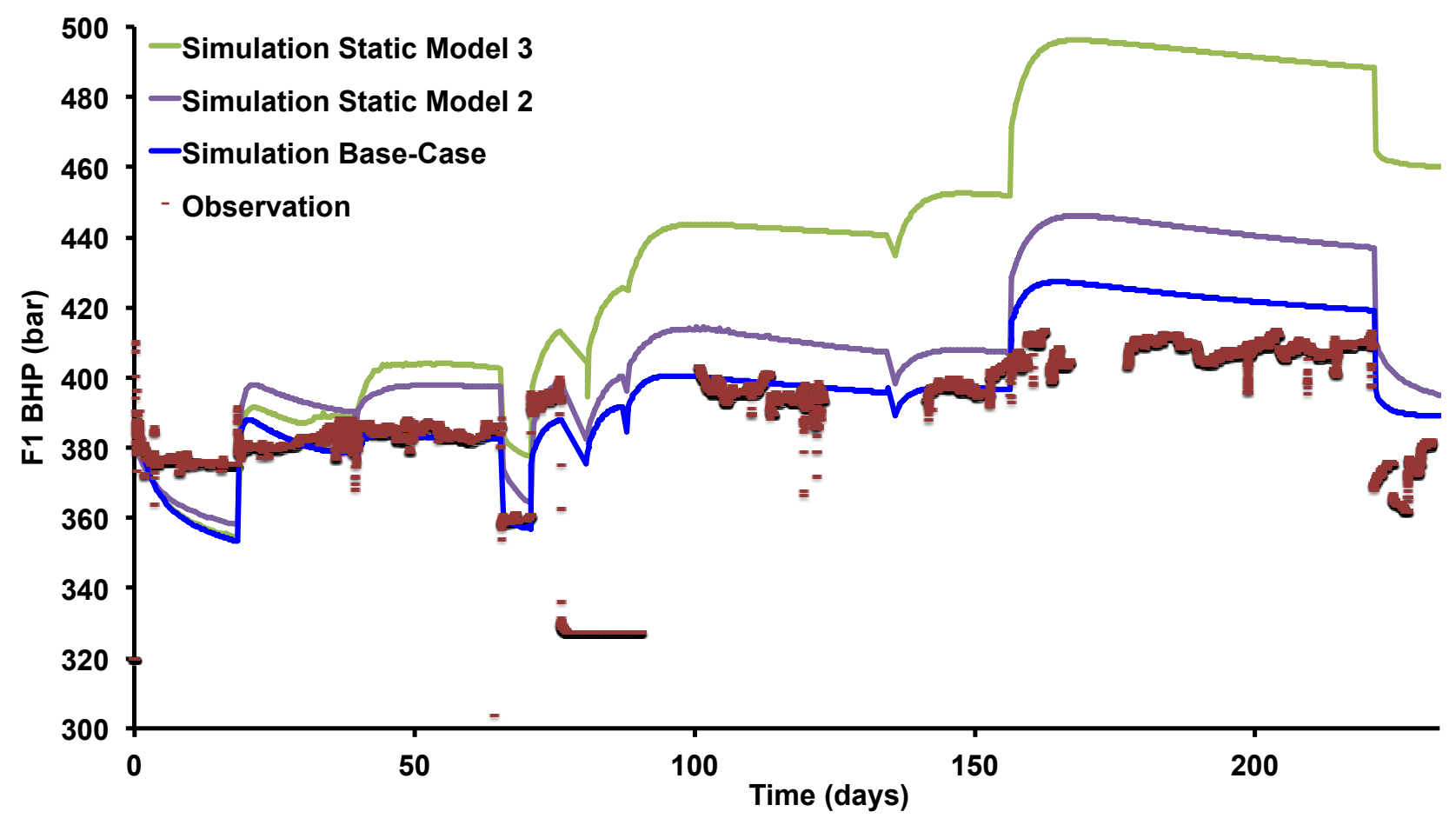

Fig.7. (color online) Observed BHP in F1 (red dots) and simulation results for 3 static model realizations, for the 230 days duration of the Cranfield pilot test. 

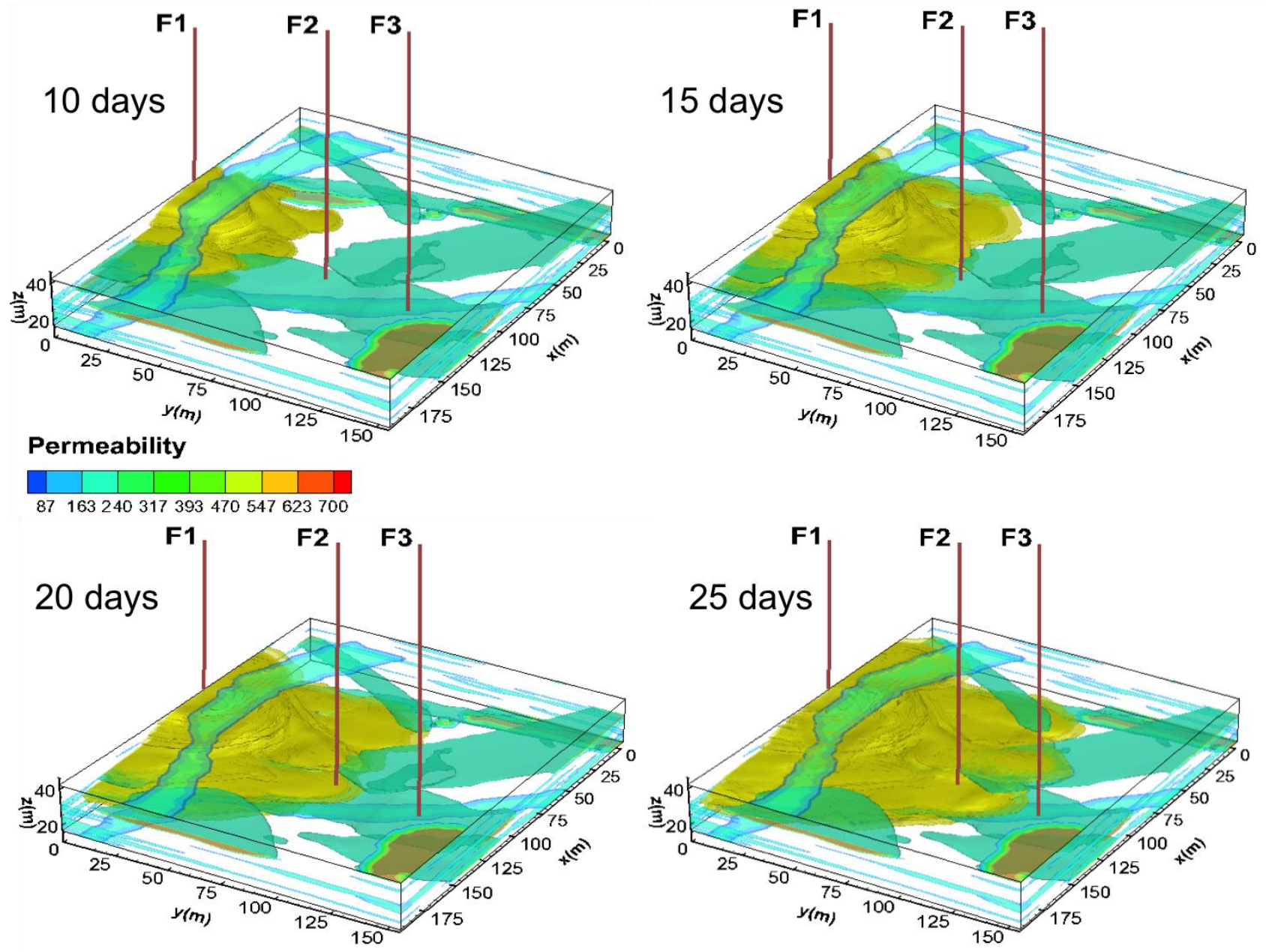

Fig. 8. (color online) Contour of $0.001 \mathrm{CO}_{2}$ molar fraction after 10, 15, 20, and 25 days of injection (yellow color). Superimposed contours of the permeability field illustrate the modeled location of depositional channels.

\section{2. $\mathrm{CO}_{2}$ breakthrough times in observation wells $\mathrm{F} 2$ and $\mathrm{F} 3$}

Table 3 lists the observed $\mathrm{CO}_{2}$ breakthrough times at observation wells $\mathrm{F} 2$ and F3 and simulation results from prior studies as well as our Base-Case simulation. The measured $\mathrm{CO}_{2}$ breakthrough time at the first observation well (F2) occurred at about 1112 days of injection. This agrees reasonably well with our simulation results, which show an increase in gas saturation at F2 after about 13 days of injection (Fig. 10). The observed $\mathrm{CO}_{2}$ breakthrough time in the second observation well (F3) was 16 days after injection, which would imply a $\sim 24 \%$ increase in average flow rate (68 $\mathrm{m}$ in 12 days, versus $112 \mathrm{~m}$ in 16 days). In our simulations, breakthrough in F3 occurs after about 26 days (Fig. 10). It seems that our high-resolution static model of the DAS can capture preferential flow paths (channels) between F1 and F2 and F3, while the upscaled static models in the cited studies only have a few grid cells spanning the DAS. The remaining discrepancy suggests that even the best-matched UTBEG permeability realization may 
have missed a preferential flow path that intersects F3. Alternatively, as discussed in Section 11, recent studies (Ajo-Franklin et al., 2013; Mukhopadhyay et al., 2015; Sun et al., 2016) suggest bottom-hole locations of F2 and F3 that are separated by only $\sim 60 \mathrm{~m}$ and $\sim 98 \mathrm{~m}$, respectively, from $\mathrm{F} 1$, rather than $68 \mathrm{~m}$ and $112 \mathrm{~m}$ in our static model. As shown below, a closer spacing between observation wells leads to better agreement between simulated and observed $\mathrm{CO}_{2}$ breakthrough times.

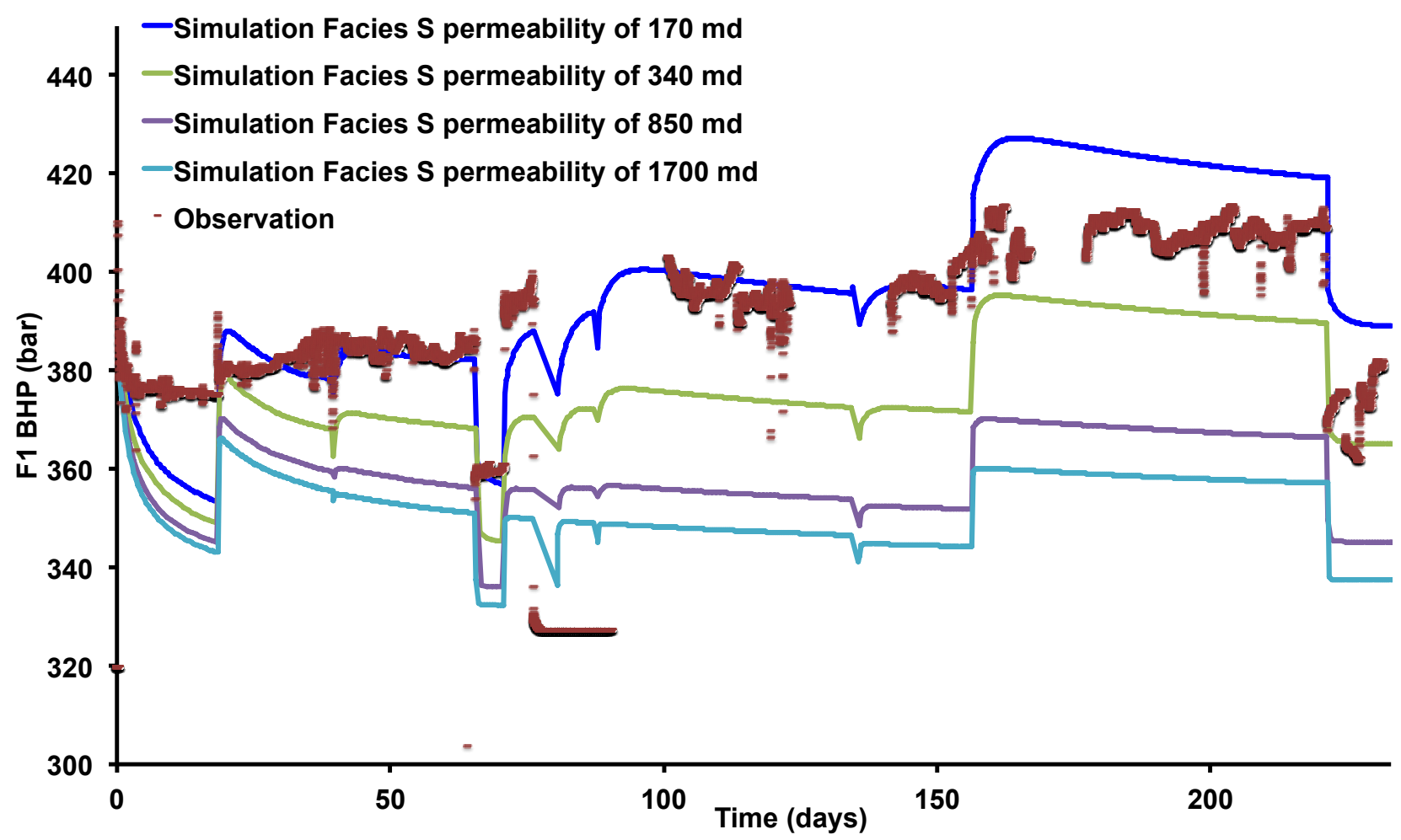

Fig.9. (color online) Observed (red dots) and simulated BHP in F1 for the 230 days duration of the Cranfield pilot test. The permeability of facies S (fluvial channel) is $170 \mathrm{md}$ in our Base-Case simulation, and is systematically increased to $340 \mathrm{md}, 850 \mathrm{md}$, and $1700 \mathrm{md}$.

Table 3 also compares the breakthrough times for simulations that use either a second-order DG or a lowest-order finite volume (FV) for transport update (Eq.(1)). The results are close, which suggests that even FV simulations have converged on the very fine grid used in this study.

Table 4 lists the breakthrough times for the simulations in which the permeability of the facies reflecting the fluvial channels is varied from the Base-Case of $170 \mathrm{md}$ to higher values of 340,850 , and $1,700 \mathrm{md}$. While a channel permeability of $340 \mathrm{md}$ improves the breakthrough time in F2, there is still a disagreement in F3 (and a poorer match to the pressure data in Fig. 9). The lateral location and connectivity of channel features are clearly a controlling factors on $\mathrm{CO}_{2}$ migration. 


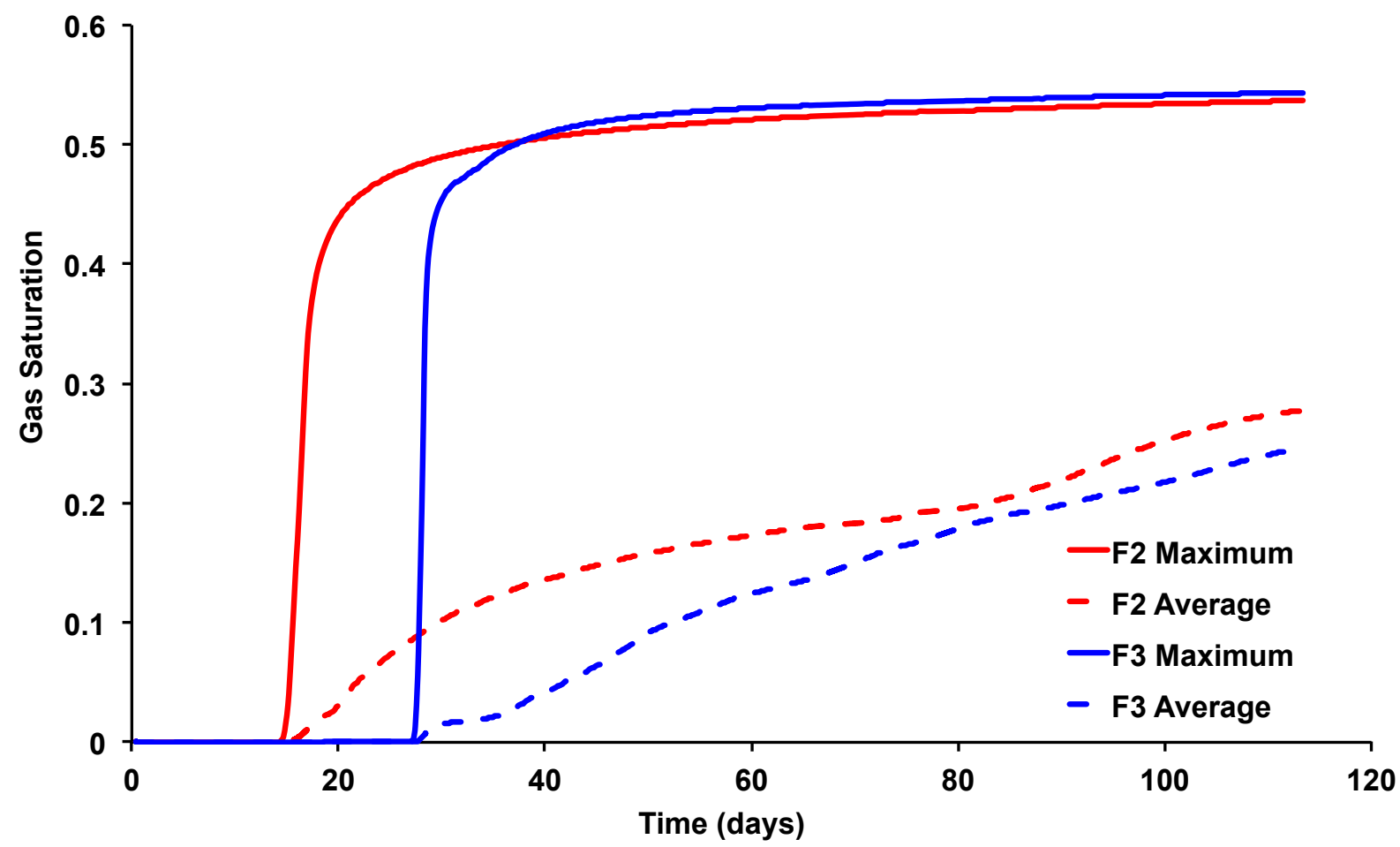

Fig. 10. Simulated gas saturation in observation wells $\mathrm{F} 2$ and $\mathrm{F} 3 . \mathrm{CO}_{2}$ breaks through in the first (F2) and second (F3) observation wells after about 13 and 26 days, respectively. Dashed lines show the gas saturation averaged over the full vertical length of the perforated intervals, while solid lines show the maximum saturations, which occur at the depths within the most permeable conduits for flow.

\section{Table 3}

$\mathrm{CO}_{2}$ breakthrough times at observation wells $\mathrm{F} 2$ and $\mathrm{F} 3$ for different simulation studies of Cranfield pilot project. The time unit is days.

\begin{tabular}{lcc}
\hline Observation well & $\mathbf{F 2}$ & $\mathbf{F 3}$ \\
Observed $^{\mathrm{a}}$ & $\mathbf{1 1}$ & $\mathbf{1 6}$ \\
\hline Delshad et al. (2013) $_{\text {Hosseini et al. }(2013)^{\mathrm{b}}}$ & 13 & 90 \\
LBNL model $^{\mathrm{c}}$ & $7,13,28,16$ & $21,28,33,46$ \\
PNNL model & 19 & 53 \\
This study: Base-Case - DG & $8-14$ & $19-53$ \\
This study: Base-Case - FV & 13.16 & 26.30 \\
\hline
\end{tabular}

afrom Hovorka et al.(2013)

${ }^{b}$ values for the best static models chosen by history matching

cfrom Mukhopadhyay et al. (2015)

\section{Table 4}

$\mathrm{CO}_{2}$ breakthrough times at observation wells $\mathrm{F} 2$ and $\mathrm{F} 3$ for simulations with different values of fluvial channel permeability. The permeability of facies S (fluvial channel) is increased to 340 , 850 , and $1700 \mathrm{md}$ compared to $170 \mathrm{md}$ in our Base-Case simulation. The time unit is days.

\begin{tabular}{ccccc}
\hline Observation well & $170 \mathrm{md}$ & $340 \mathrm{md}$ & $850 \mathrm{md}$ & $1700 \mathrm{md}$ \\
\hline F2 & 13.16 & 10.8 & 9.2 & 8.4 \\
F3 & 26.3 & 22.2 & 21.4 & 20.5 \\
\hline
\end{tabular}




\section{Sensitivity analysis of relative permeability parameter values}

Iglauer et al. (2015) provides a comprehensive review of the challenges in contact angle experiments and wettability in GCS. Experimental measurements of endpoint relative permeabilities in $\mathrm{CO}_{2}$ core flood experiments are notoriously difficult (see Levine, 2011 and Levine et al., 2014). Experimental results show low values of endpoint $\mathrm{CO}_{2}$ relative permeability $(<0.5)$ and high values of residual water saturation $(>0.4)$ under drainage conditions (Yoshida et al., 2016). However, reported data for Cranfield have a high value for the end-point $\mathrm{CO}_{2}$ relative permeability (see Table 2). To investigate the importance of this potential uncertainty, we perform a series of additional simulations to assess the impact of relative permeability parameters on injection BHP and $\mathrm{CO}_{2}$ breakthrough times. Specifically, we vary the endpoint $\mathrm{CO}_{2}$ relative permeability $\left(k_{r g}^{0}\right)$, brine residual saturation $\left(S_{w, i r}\right)$, curvature exponents of gaseous $\mathrm{CO}_{2}$ $(m)$, and curvature exponents of brine $(n)$. Numerical simulations of the Cranfield pilot project using high-resolution static models provide an opportunity to test the effect of relative permeability parameters and compare the results with field measured data of pressure responses and $\mathrm{CO}_{2}$ breakthrough times.

\section{Table 5}

$\mathrm{CO}_{2}$ breakthrough times at observation wells $\mathrm{F} 2$ and $\mathrm{F} 3$ for simulations with different values of brine residual saturation. The bold values correspond to the Base-Case simulation. The time unit is days.

\begin{tabular}{cccccccccc}
\hline Observation well & 0.0 & 0.1 & 0.2 & 0.3 & $\mathbf{0 . 4}$ & 0.5 & 0.6 & 0.7 & 0.8 \\
\hline F2 & 20.5 & 19.3 & 17.9 & 15.1 & $\mathbf{1 3 . 1 6}$ & 10.9 & 9.3 & 6.6 & 4.7 \\
F3 & 52.2 & 47.6 & 31.8 & 29.2 & $\mathbf{2 6 . 3}$ & 23.4 & 20.8 & 16.5 & 11.5 \\
\hline
\end{tabular}

\subsection{Sensitivity to brine residual saturation}

Fig. 11 shows how the simulated BHP in F1 is affected by varying the brine residual saturation $\left(S_{w, i r}\right)$ from 0.0 to 0.8 . Table 5 lists the corresponding $\mathrm{CO}_{2}$ breakthrough times at observation wells F2 and F3. We find that higher residual saturations result in a lower BHP at all times, but also that the pressure jumps are reduced for $S_{w, i r}$ larger than 0.4. Interestingly, a residual water saturation of 0.6 shows comparable agreement to the measured data at early times, but a much better match after 157 days when $\mathrm{CO}_{2}$ is injected at the highest rate. In addition, the breakthrough times are also closer to the field data for a $S_{w, i r}$ of 0.6 . Both the pressure response and the breakthrough times are sensitive to $S_{w, i r}$. 


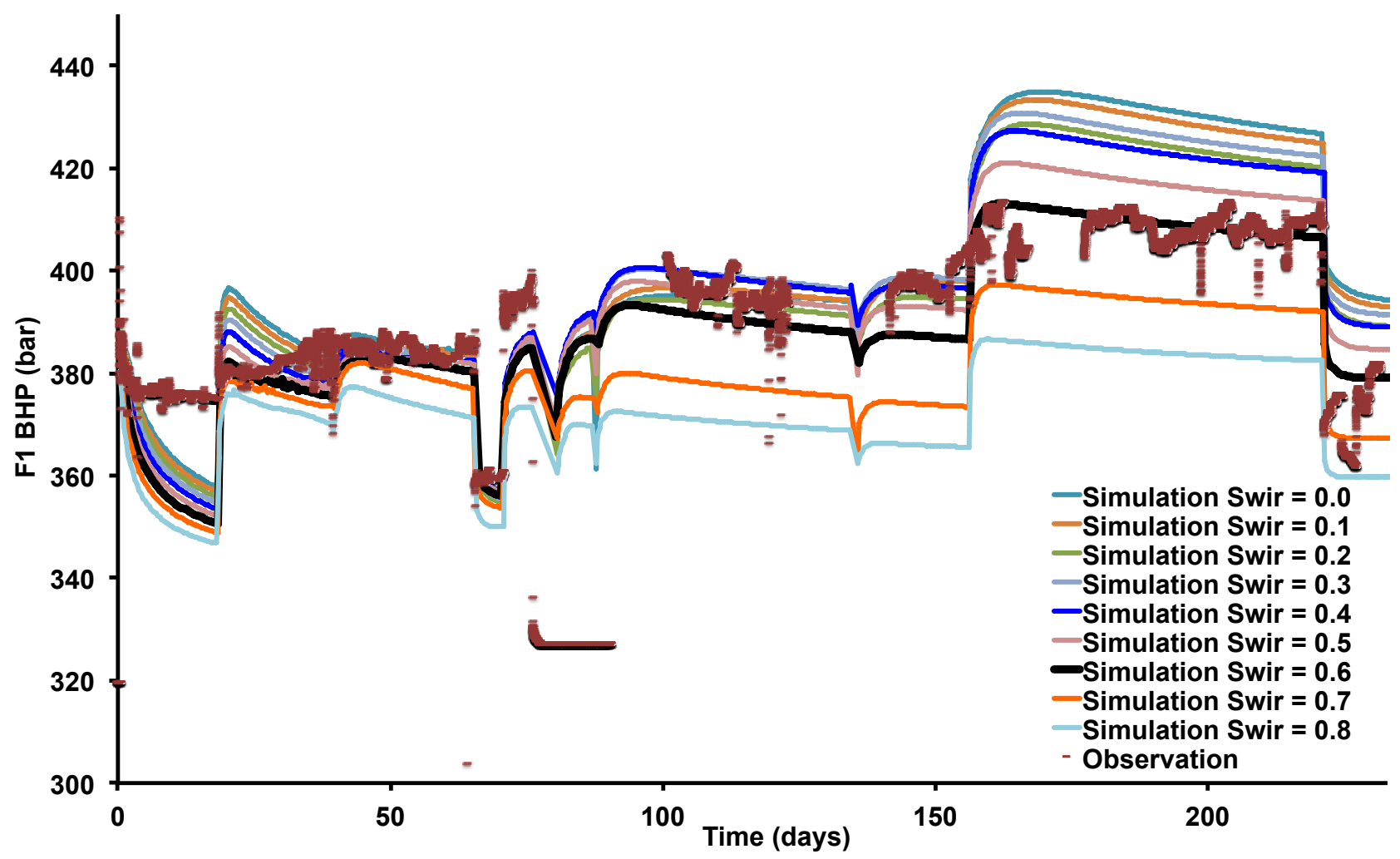

Fig.11. (color online) Sensitivity to brine residual saturation, with $S_{w, i r}=0.4$ in the Base-Case.

\subsection{Sensitivity to end-point $\mathrm{CO}_{2}$ relative permeability}

We vary the $\mathrm{CO}_{2}$ (gas) end-point relative permeability $\left(k_{r g}^{0}\right)$ from 0.2 to 1.0 . The simulated BPH in F1 is given in Fig. 12 and breakthrough times in Table 6. As in Yoshida et al. (2016), we find that the results are sensitive to the $\mathrm{CO}_{2}$ end-point relative permeability. Small values of $k_{r, g}^{0}$ dramatically increase the BHP in the injection well due to low gas mobility, which also delays the breakthrough times. The values chosen in Delshad et el. (2013) and Hosseini et al. (2013) also provide the best agreement between observations and our simulations.

Table 6

$\mathrm{CO}_{2}$ breakthrough times at observation wells $\mathrm{F} 2$ and $\mathrm{F} 3$ for simulations with different values of end-point $\mathrm{CO}_{2}$ relative permeability. The bold values correspond to the Base-Case simulation. The time unit is days.

\begin{tabular}{cccccccccccc}
\hline Observation well & 0.06 & 0.1 & 0.2 & 0.3 & 0.4 & 0.5 & 0.6 & 0.7 & $\mathbf{0 . 8}$ & 0.9 & 1.0 \\
\hline F2 & 25.1 & 23.0 & 20.0 & 18.1 & 16.3 & 15.4 & 14.5 & 13.7 & $\mathbf{1 3 . 1 6}$ & 12.7 & 12.3 \\
F3 & 52.9 & 48.9 & 41.1 & 35.8 & 32.7 & 30.6 & 28.8 & $\mathbf{2 7 . 4}$ & $\mathbf{2 6 . 3}$ & 25.3 & 24.6 \\
\hline
\end{tabular}




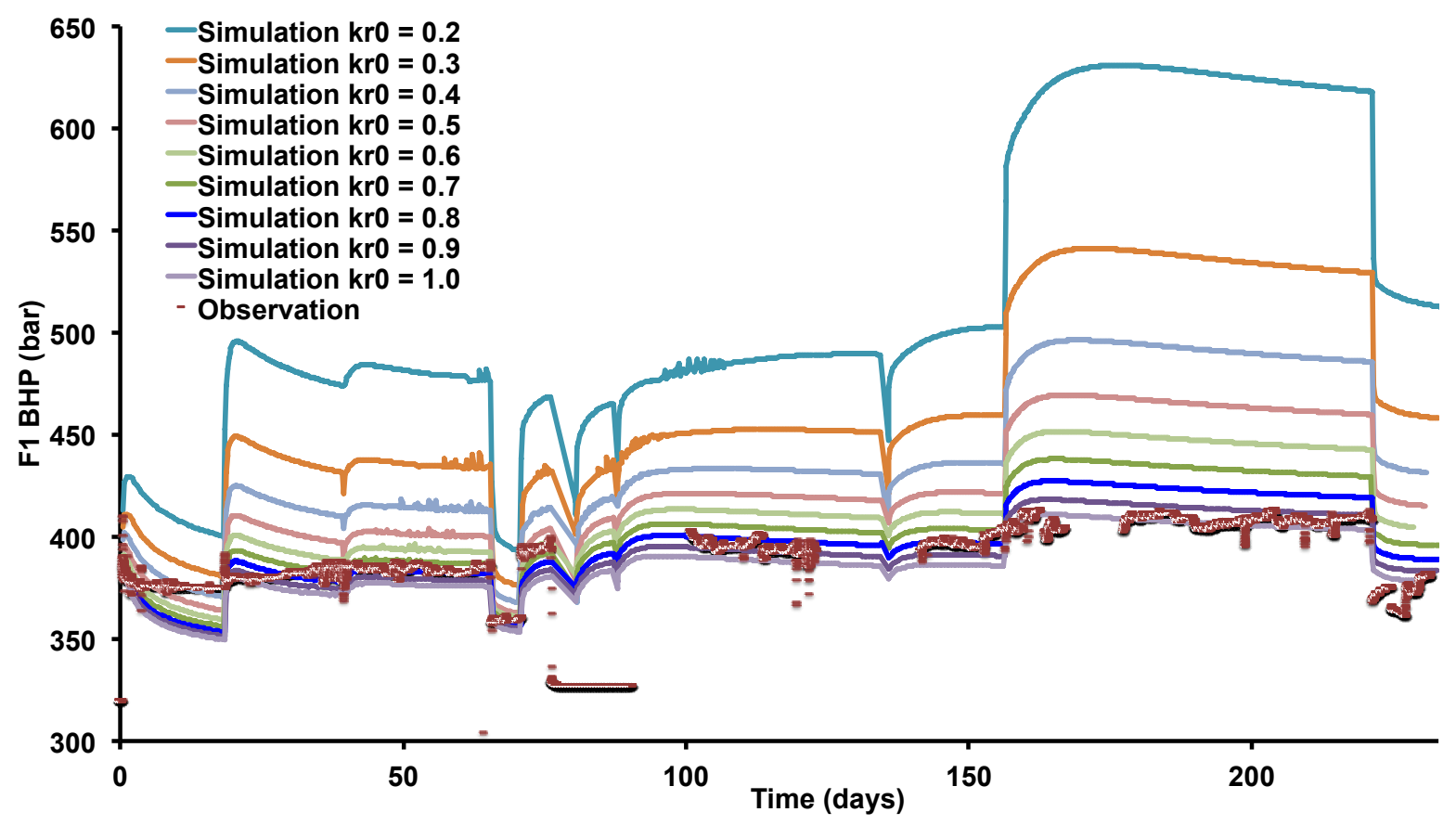

Fig.12. (color online) Sensitivity to end-point $\mathrm{CO}_{2}$ relative permeability, with $k_{r g}^{0}=0.8$ in the BaseCase.

\subsection{Sensitivity to $\mathrm{CO}_{2}$ and brine curvature exponents}

We change the $\mathrm{CO}_{2}$ and brine curvature exponents ( $m$ and $n$ ) from linear relationships ( $m=n=1$ ) to high values of 6 to study their effect on the pressure response and the $\mathrm{CO}_{2}$ breakthrough times at observation wells F2 and F3. Fig. 13a and Fig. 13b show how increasing curvature exponents influence the simulated BHP in the injection well. Table $7 \mathrm{a}$ and Table $7 \mathrm{~b}$ list the $\mathrm{CO}_{2}$ breakthrough times at observation wells $\mathrm{F} 2$ and $\mathrm{F} 3$ for $\mathrm{CO}_{2}$ and brine curvature exponents, respectively. Increasing $\mathrm{CO}_{2}$ and brine exponents result in higher BHP in the injection well. The simulations are more sensitive to the $\mathrm{CO}_{2}$ exponent. As seen in Fig. 13 linear curvature exponents for $\mathrm{CO}_{2}$ and brine underpredict the $\mathrm{BHP}$ in the injection well. Importantly, increasing the $\mathrm{CO}_{2}$ curvature exponent results in later breakthrough times.

\section{Table 7a}

$\mathrm{CO}_{2}$ breakthrough times at observation wells $\mathrm{F} 2$ and $\mathrm{F} 3$ for simulations with different values of the $\mathrm{CO}_{2}$ curvature exponent. The bold values correspond to the Base-Case simulation. The time unit is days.

\begin{tabular}{cccccc}
\hline Observation well & $m=n=1$ & $m=1.2$ & $\mathbf{m = 2 . 6}$ & $m=4.2$ & $m=6$ \\
F2 & 3 & 4.2 & $\mathbf{1 3 . 1 6}$ & 19.4 & 23.1 \\
F3 & 5.2 & 11.3 & $\mathbf{2 6 . 3}$ & 35.5 & 47 \\
\hline
\end{tabular}




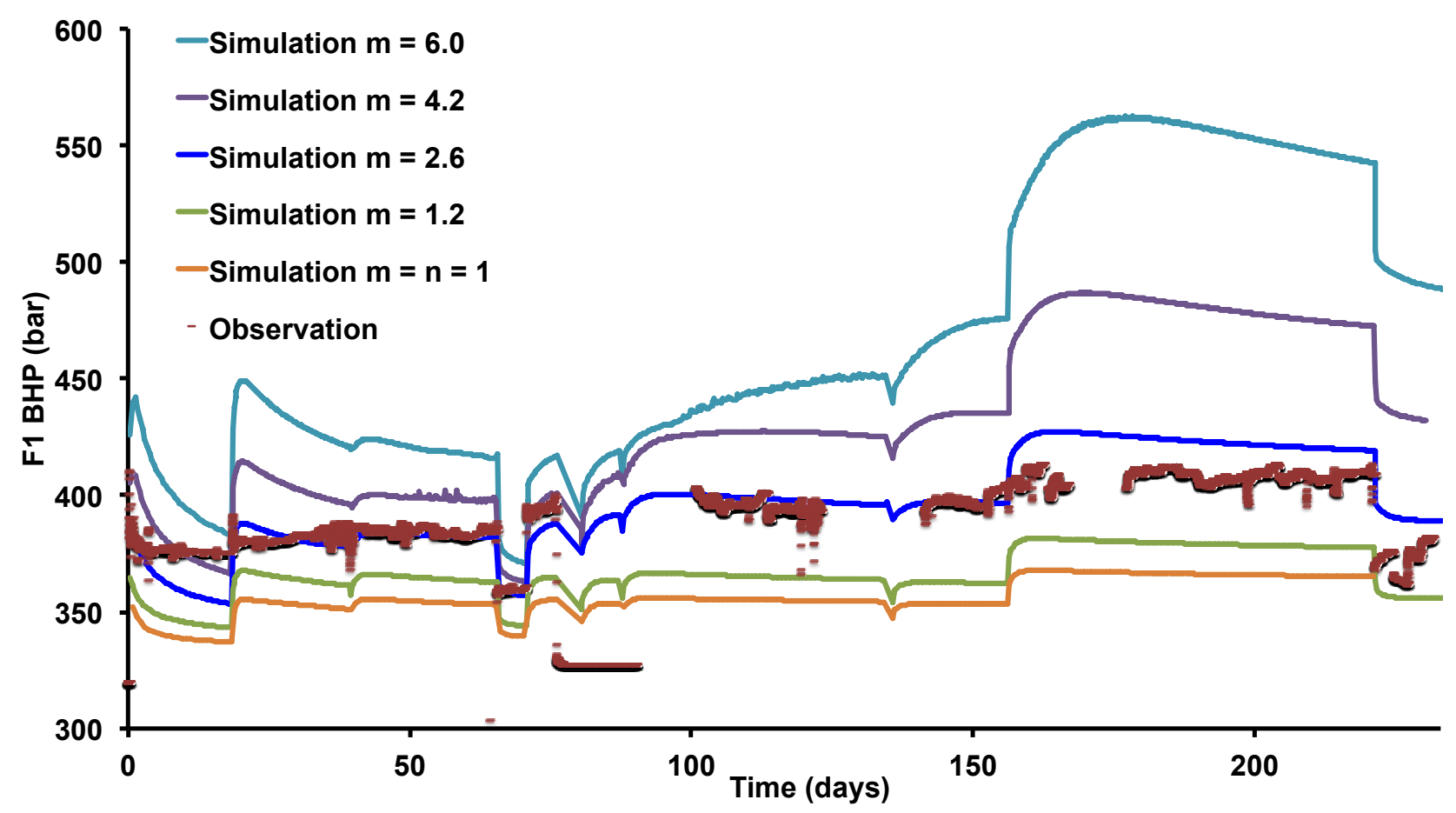

Fig.13a. (color online) Pressure response for different $\mathrm{CO}_{2}$ curvature exponents, with $m=2.6$ kept as in the Base-Case, except for the simulation with $m=n=1$.

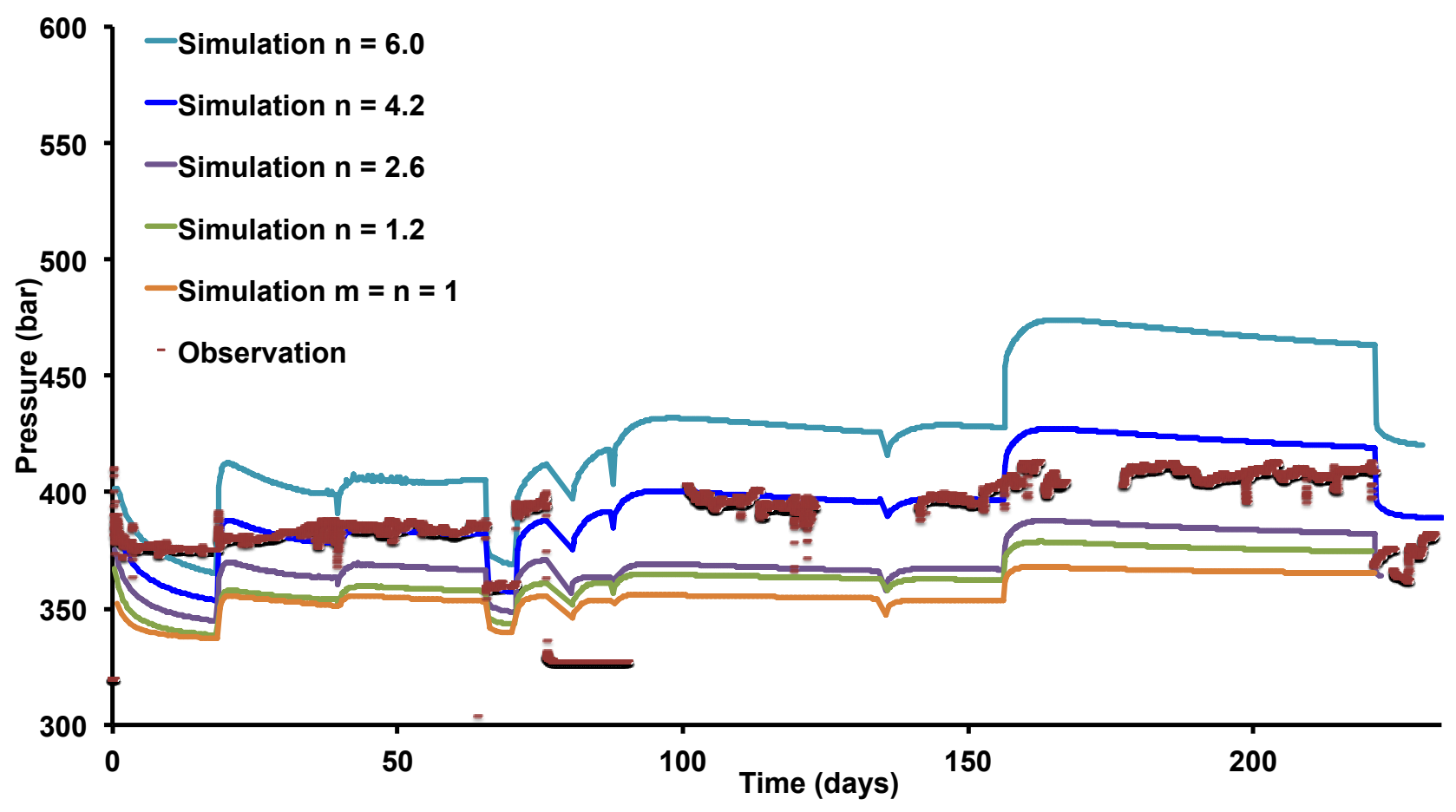

Fig.13b. (color online) Pressure response for different brine curvature exponents, with $n=4.2$ kept as in the Base Case, except for the simulation with $m=n=1$. 


\section{Table 7b}

$\mathrm{CO}_{2}$ breakthrough times at observation wells $\mathrm{F} 2$ and F3 for simulations with different values of the brine curvature exponent. The bold values correspond to the Base-Case simulation. The time unit is days.

\begin{tabular}{cccccc}
\hline Observation well & $m=n=1$ & $n=1.2$ & $n=2.6$ & $\boldsymbol{n = 4 . 2}$ & $n=6$ \\
\hline F2 & 3 & 15.7 & 13.3 & $\mathbf{1 3 . 1 6}$ & 12.7 \\
F3 & 5.2 & 25.5 & 25.4 & $\mathbf{2 6 . 3}$ & 26.6 \\
\hline
\end{tabular}

\section{Effect of Fickian diffusion}

To investigate the importance of Fickian diffusion, we performed simulations with both $D=1.33 \mathrm{~m}^{2} / \mathrm{sec}$, and with $D=0$. We find that the pressure response and the breakthrough times are nearly identical for both simulations. This is due to the high injection rates (high Péclet numbers for advection dominated flow) and short duration of the pilot test. Fickian diffusion is expected to be important for the longer-term evolution of the $\mathrm{CO}_{2}$ plume post injection. Steep compositional gradients between the $\mathrm{CO}_{2}$-filled preferential flow paths will slowly diffuse into the mostly water-saturated lower permeability clay-rich facies. This cross-flow effect delays the spreading of the plume over larger time-scales.

\section{Effect of capillarity}

Capillary pressures are scaled by the Leverett $J$-function $(J=\sqrt{/ K})$ to account for variations in permeability and porosity. As a reference curve, we use the capillary pressure function in Hosseini et al. (2013) and Delshad et al. (2013). Fig. 14 shows the simulated BHP in F1 with and without considering capillary effects. Unlike the findings in Delshad et al. (2013) we do not find a significant impact of capillarity on the pressure response during the injection period. This is because injection rates are high, while the reported capillary pressures are only of the order of $\mathrm{KPa}$. When we increase the capillary pressures by a factor of 10 and 20, we do see an increased pressure response at later times because $\mathrm{CO}_{2}$ has a harder time invading the low permeability facies. 


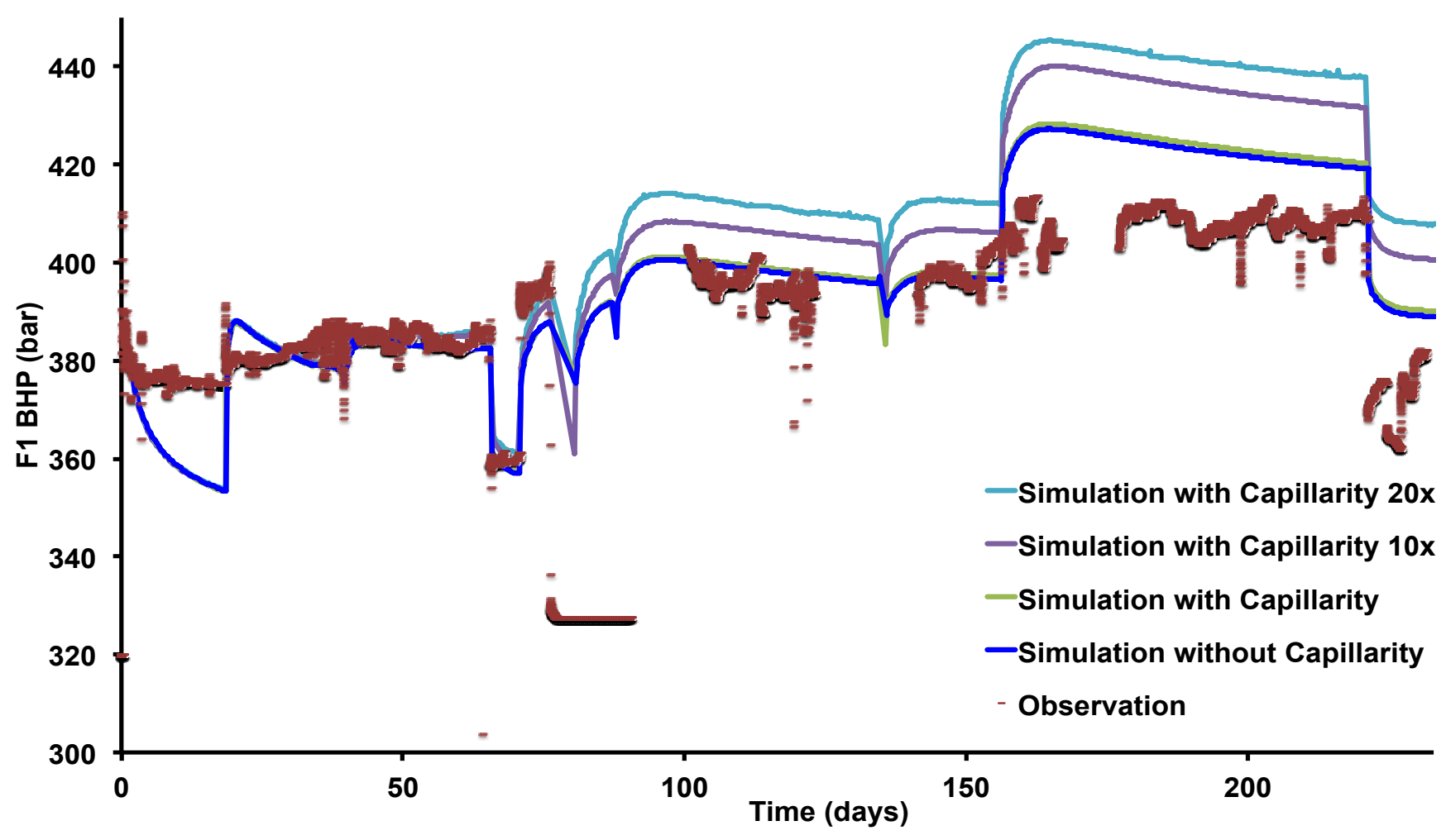

Fig. 14. Observed and simulated injection BHP with and without considering capillary effects. The 10x, 20x, cases correspond to increasing capillary pressures by a factor of 10 and 20, respectively

\section{Location of observation wells}

In the simulation results presented in previous sections we used the observation wells (F2 and F3) separated by distance of $44 \mathrm{~m}$ which are located $68 \mathrm{~m}$ and $112 \mathrm{~m}$ away from the injection well (F1). These locations are based on the static models developed by Hosseini et al. (2013), and used by Delshad et al. (2013). However, AjoFranklin et al. (2013) used high-resolution characterization of a $\mathrm{CO}_{2}$ plume using crosswell seismic tomography, and they reported $30 \mathrm{~m}$ distances between F2 and F3. Similar distances were also used in the Sim-SEQ project (Mukhopadhyay et al., 2015). Sun et al. (2016) reported the bottom-hole distance between F1 and F2 as $60 \mathrm{~m}$ and between $\mathrm{F} 1$ and F3 as $93 \mathrm{~m}$ with F2 and F3 separated by $33.5 \mathrm{~m}$. The discrepancy in well locations reported in the literature motivates us to do another sensitivity study (see Fig. 15). We find that simulated breakthrough times agree better with field data for the aforementioned closer distance between $\mathrm{F} 2$ and F3. By placing F3 at $98 \mathrm{~m}$ the $\mathrm{CO}_{2}$ breakthrough time is 21.8 days as compared to the value of 26.3 days when F3 is located in $112 \mathrm{~m}$ away from the injector. Breakthrough at $60 \mathrm{~m}$ occurs at 10.5 days, very close to the observed breakthrough time of 11 days in F2.

In section 8.1 we showed that a residual water saturation of 0.6 shows good agreement with the BHP in the injection well for the full duration of the pilot project. Placing F3 at $98 \mathrm{~m}$ and assuming a residual water saturation of 0.6 results in $\mathrm{CO}_{2}$ 
breakthrough time of 16 days, which is in perfect agreement with the field observation. Note that irreducible water saturations were carefully measured for well cores, but residual saturations and relative permeabilities can vary for different facies throughout a formation. It is not inconceivable that a different average, or effective, relative permeability relation (including residual saturations) is more appropriate to describe the global flow paths.
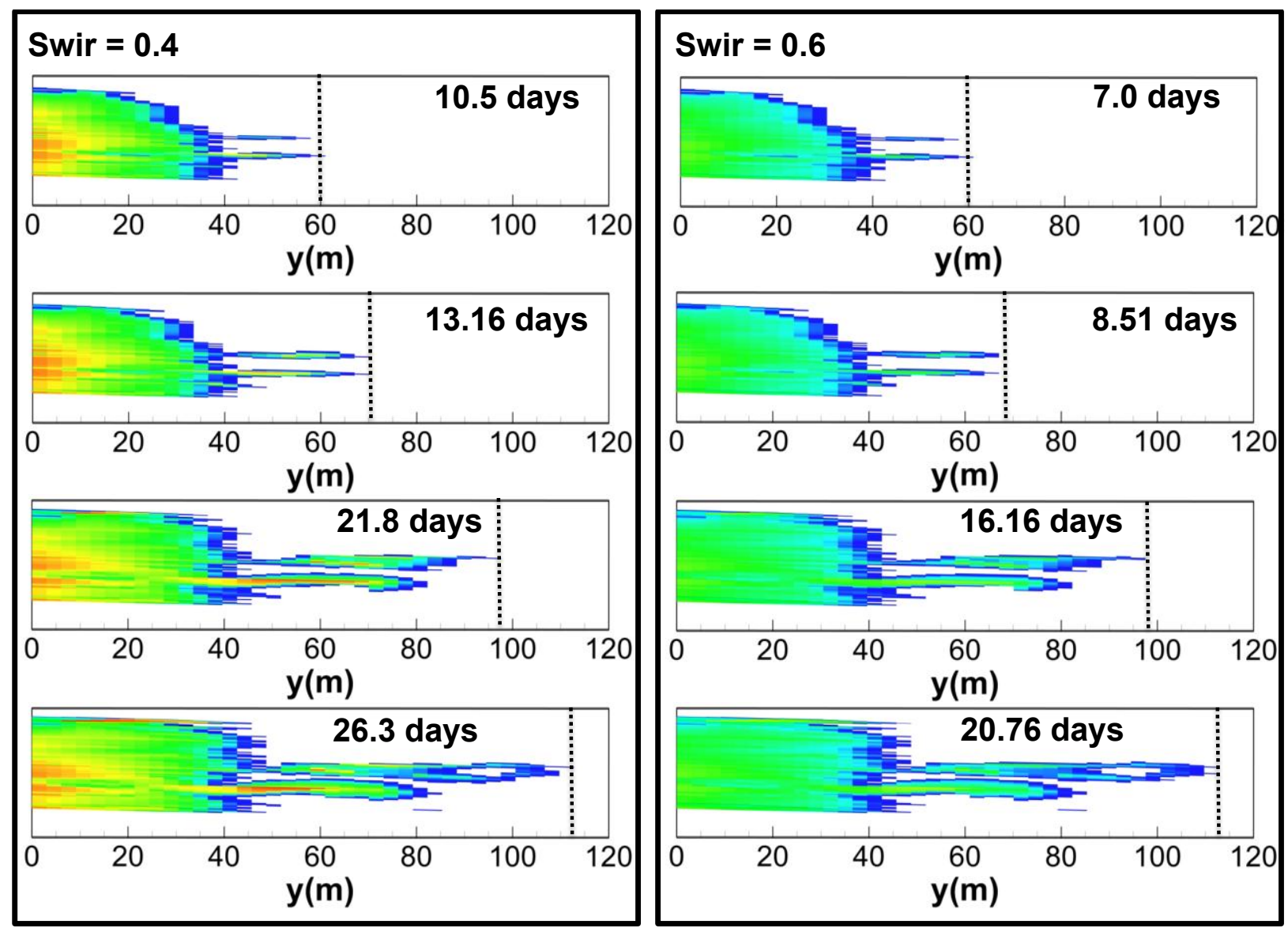

Gas saturation:

$\begin{array}{llllllllll}0.05 & 0.10 & 0.15 & 0.20 & 0.25 & 0.30 & 0.35 & 0.40 & 0.45 & 0.50\end{array}$

Fig. 15. Location of the $\mathrm{CO}_{2}$ front at different times, with $S_{w, i r}=0.4$ in the Base-Case shown in the left panel and $S_{w, i r}=0.6$ in the right panel.

\section{Conclusions}

The Cranfield pilot project provides one of the richest data sets to study geological carbon dioxide sequestration in large-scale brine aquifers. Yet, measurements of subsurface processes are inherently limited and numerical simulations of carbon dioxide sequestration are invaluable to further constrain uncertainties. Multiple simulations studies have been published in recent years that model the flow and transport of $\mathrm{CO}_{2}$ throughout the entire Cranfield site (Hosseini et al., 2013; Delshad et al., 2013; 
Mukhopadhyay et al., 2012, 2015) using upscaled static models for the permeability and porosity fields. In this work, we focus on a Detailed Area of Study (DAS) that includes the injection well and two nearby observation wells. Due to the smaller size of the DAS we are able to use the most detailed history-matched static models for the formation characterization. These petrophysical models have a vertical resolution of only 1 foot. In addition, we use advanced reservoir simulation tools, such as higher-order finite elements and accurate EOS-based modeling of phase behavior and thermodynamic phase-split computations. On one hand, we are reassured to find good qualitative agreement with prior studies that used a range of well-established reservoir simulators. One the other hand, by using the highest-resolution static model in combination with advanced numerical methods and robust physical models our simulation results are quantitatively the closest yet to the measured field data. This is important because in future work, we plan to also model the perfluorocarbon (and other) tracers that were injected in different pulses as part of the Cranfield pilot project (Hovorka, 2011).

Extensive sensitivity studies further help to identify potential causes of earlier discrepancies between measured and simulated results. Relative permeabilities, for instance, may vary for different rock types (facies). Measurements for cores from a limited number of wells may not necessarily represent the effective relative permeability throughout a formation. We find that simulations with an irreducible water saturation of $60 \%$ agree much better with the observed pressure response and $\mathrm{CO}_{2}$ breakthrough times than the $40 \%$ used in previous studies. A different porosity distribution could have a similar effect (immobile brine acts as an effective porosity reduction). There is also some disagreement in the literature regarding the bottom-hole location of the monitoring wells $\mathrm{F} 2$ and $\mathrm{F} 3$. We find the best agreement with $\mathrm{CO}_{2}$ breakthrough times when $\mathrm{F} 2$ is located $\sim 60-68 \mathrm{~m}$ from F1, and F3 at $98 \mathrm{~m}$ from F1 (as in Ajo-Franklin et al., 2013; Mukhopadhyay et al., 2015; Sun et al., 2016).

General conclusions from the sensitivity analyses are as follows:

(1) The most critical uncertainties relate to heterogeneous permeability and porosity fields. Cranfield, like many candidate GCS and $\mathrm{CO}_{2}$-EOR sites, consists of fluvial deposits that exhibit channelized conduits of high permeability flow pathways, interspersed with tighter facies. 3D seismic data and core samples from a small number of exploration wells provide only limited information on the volume fractions and connectivity of different facies throughout the aquifer. The facies architecture, though, is the primary factor that determines the flow and transport of $\mathrm{CO}_{2}$. For example, the arrival time (breakthrough) of the $\mathrm{CO}_{2}$ displacement front at any particular location (e.g., an observation well) is largely determined by whether or not it happens to be intersected by (or lies close to) one or more of the fluvial channels. Our simulations for three of the best historymatched realizations of high-resolution petrophysical models still show quite a wide spread in breakthrough times and pressure responses. Similarly, we show that the results are sensitive to the mean permeability in the fluvial channels.

(2) The flow rates of injected $\mathrm{CO}_{2}$ are directly proportional to its relative permeability, which is therefore an important parameter. Low gas relative 
permeabilities result in a slower spreading of the $\mathrm{CO}_{2}$ plume and more pressure build-up, while a high relative permeability contrast with respect to brine can result in a viscously unstable displacement front. The latter can result in viscous fingering (in addition to permeability channeling), which makes predicting the location of the $\mathrm{CO}_{2}$ front more challenging. Relative permeabilities are non-trivial to measure and depend strongly on the rock types. Even accurate measurements on one core sample may not represent the relative permeability in different facies types throughout the formation. To complicate matters further, $\mathrm{CO}_{2}$ is known to alter the wettability of rock under certain conditions. Our parameter studies for different residual water saturations, gas end-point relative permeabilities, and curvature exponents demonstrate how sensitive simulation results are to accurate measurements of appropriate relative permeabilities.

(3) Fickian diffusion and capillarity are shown to be less important for the early time evolution of the $\mathrm{CO}_{2}$ plume, because injection rates are high and flow is dominated by advection. Both of these processes are expected to be more important for the post-injection long-term migration of $\mathrm{CO}_{2}$, by driving cross-flow between more gas-saturated high permeability facies and more brine-saturated facies like clay-rich. These processes enhance the mixing of $\mathrm{CO}_{2}$ and brine and delay the spreading of $\mathrm{CO}_{2}$.

Constraining the uncertainties in spatially variable permeabilities and porosities of fluvial depositional facies (and their associated relative permeabilities) is clearly paramount for accurate predictions of the faith of $\mathrm{CO}_{2}$ in GCS applications. This requires new observables in addition to pressure data and $\mathrm{CO}_{2}$ arrival times in observation wells. Natural (e.g, isotopes) and introduced (e.g., perfluorocarbons, $\mathrm{SF}_{6}$, and noble gasses) tracers can provide such additional information. For instance, by measuring the arrival times of small amounts of tracers that are co-injected with $\mathrm{CO}_{2}$ at a particular time, one can determine flow rates at different times (e.g, for different injection rates), while the arrival of the $\mathrm{CO}_{2}$ displacement front itself can only be measured once. These additional degrees of freedom can be used to characterize a GCS target formation's geology in even more detail than in this study. Incorporating such tracer measurements at the Cranfield site into reservoir modeling is the subject of ongoing work as part of the project referenced in the acknowledgements.

\section{Acknowledgements}

This manuscript has been coauthored by UT-Battelle, LLC under Contract No. DEAC05-00OR22725 with the U.S. Department of Energy. The United States Government retains and the publisher, by accepting the article for publication, acknowledges that the United States Government retains a non-exclusive, paid-up, irrevocable, worldwide license to publish or reproduce the published form of this manuscript, or allow others to do so, for United States Government purposes. The Department of Energy will provide public access to these results of federally sponsored research in accordance with the DOE Public Access Plan (http://energy.gov/downloads/doe-public-access-plan). 


\section{References}

Acs, G., Doleschall, S. and Farkas, E., 1985. General purpose compositional model. SPE J. 25(04), 543-553.

Ajo-Franklin, J.B., Peterson, J., Doetsch, J. and Daley, T.M., 2013. High-resolution characterization of a $\mathrm{CO}_{2}$ plume using cross-well seismic tomography: Cranfield, MS, USA. Int. J. Greenh. Gas Control. 18, 497-509.

Ampomah, W., Balch, R., Cather, M., Rose-Coss, D., Dai, Z., Heath, J. E, Dewers, T., Mozley, P. 2016. Evaluation of $\mathrm{CO}_{2}$ Storage Mechanisms in $\mathrm{CO}_{2}$ Enhanced Oil Recovery Sites: Application to Morrow Sandstone Reservoir. Energy Fuels, doi: 10.1021/acs.energyfuels.6b01888.

Ampomah, W., Balch, R.S., Grigg, R.B., McPherson, B., Will, R.A., Lee, S.Y., Dai, Z. and Pan, F., 2016. Co- optimization of $\mathrm{CO}_{2}-\mathrm{EOR}$ and storage processes in mature oil reservoirs. Greenhouse Gases: Science and Technology, doi: 10.1002/ghg.1618.

Arts, R., Eiken, O., Chadwick, A., Zweigel, P., Van der Meer, L. and Zinszner, B., 2004. Monitoring of $\mathrm{CO}_{2}$ injected at Sleipner using time-lapse seismic data. Energy, 29(9), 1383-1392.

Bachu, S., 2000. Sequestration of $\mathrm{CO}_{2}$ in geological media: criteria and approach for site selection in response to climate change. Energ. Convers. and Manage. 41(9), 953970.

Bacon, D.H., Qafoku, N.P., Dai, Z., Keating, E.H. and Brown, C.F., 2016. Modeling the impact of carbon dioxide leakage into an unconfined, oxidizing carbonate aquifer. Int. J. Greenh. Gas Control. 44, 290-299.

Baines, S.J. and Worden, R.H., 2004. Geological storage of carbon dioxide. Geological Society, London, Special Publications. 233(1), 1-6.

Brooks, R.H., Corey, A.T., 1964. Hydraulic properties of porous media. Hydrological Papers. Colorado State University.

Bridge, J.S., 2009. Rivers and floodplains: forms, processes, and sedimentary record. John Wiley \& Sons.

Binning, P. and Celia, M.A., 1999. Practical implementation of the fractional flow approach to multi-phase flow simulation. Adv. Water Resour. 22(5), 461-478.

Dai, Z., Middleton, R., Viswanathan, H., Fessenden-Rahn, J., Bauman, J., Pawar, R.,Lee, S., McPherson, B., 2014a. An integrated framework for optimizing $\mathrm{CO}_{2}$ sequestration and enhanced oil recovery. Environ. Sci. Technol. Lett. 1, 49-54. 
Dai, Z., Keating, E., Bacon, D., Viswanathan, H., Stauffer, P., Jordan, A. and Pawar, R., 2014b. Probabilistic evaluation of shallow groundwater resources at a hypothetical carbon sequestration site. Sci. Rep. 4, doi: 10.1038/srep04006.

Dai, Z., Stauffer, P.H., Carey, J.W., Middleton, R.S., Lu, Z., Jacobs, J.F., HnottavangeTelleen, K. and Spangler, L.H., 2014c. Pre-site characterization risk analysis for commercial-scale carbon sequestration. Environ. Sci. Technol. 48(7), 3908-3915.

Dai, Z., Viswanathan, H., Middleton, R., Pan, F., Ampomah, W., Yang, C., Jia, W., Xiao, T., Lee, S.Y., McPherson, B. and Balch, R., 2016. $\mathrm{CO}_{2}$ Accounting and Risk Analysis for $\mathrm{CO}_{2}$ Sequestration at Enhanced Oil Recovery Sites. Environ. Sci. Technol.50 (14), 7546-7554, DOI: 10.1021/acs.est.6b01744.

Dance, T., Patterson, L., 2016. Observations of carbon dioxide saturationdistribution and residual trapping using core analysis and repeatpulsed-neutron logging at the $\mathrm{CO}_{2}$ CRC Otway site. Int. J. Greenh. Gas Control. 47, 210-220.

Delshad, M. and Pope, G.A., 1989. Comparison of the three-phase oil relative permeability models. Transport Porous Med. 4(1), 59-83.

Delshad, M., Kong, X., Tavakoli, R., Hosseini, S.A. and Wheeler, M.F., 2013. Modeling and simulation of carbon sequestration at Cranfield incorporating new physical models. Int. J. Greenh. Gas Control. 18, 463-473

Deveugle, P.E., Jackson, M.D., Hampson, G.J., Farrell, M.E., Sprague, A.R., Stewart, J. and Calvert, C.S., 2011. Characterization of stratigraphic architecture and its impact on fluid flow in a fluvial-dominated deltaic reservoir analog: Upper Cretaceous Ferron Sandstone Member, Utah. AAPG bulletin. 95(5), 693-727.

DOE-NETL (U.S. Department of Energy - National Energy Technology Laboratory), 2015. Carbon Storage Atlas Fifth Editions. https://www.netl.doe.gov/research/coal/carbon-storage/natcarb-atlas.

Emberley, S., Hutcheon, I., Shevalier, M., Durocher, K., Mayer, B., Gunter, W.D. and Perkins, E.H., 2005. Monitoring of fluid-rock interaction and $\mathrm{CO}_{2}$ storage through produced fluid sampling at the Weyburn $\mathrm{CO}_{2}$-injection enhanced oil recovery site, Saskatchewan, Canada. Appl. Geochem. 20(6),1131-1157.

Freiburg, J.T., Morse, D.G., Leetaru, H.E., Hoss, R.P., Yan, Q., 2014. A Depositional and Diagenetic Characterization of the Mt. Simon Sandstone at the Illinois BasinDecatur Project Carbon Capture and Storage Site. Circular 583, IllinoisState Geological Survey, Decatur, Illinois, USA, $53 \mathrm{p}$.

Freifeld, B.M., Trautz, R.C., Kharaka, Y.K., Phelps, T.J., Myer, L.R., Hovorka, S.D. and Collins, D.J., 2005. The U-tube: a novel system for acquiring borehole fluid samples from a deep geologic $\mathrm{CO}_{2}$ sequestration experiment. J. Geophys. Res. 110 (B10). 
Firoozabadi, A., 2015. Thermodynamics and Applications of Hydrocarbon Energy Production. McGraw Hill Professional.

Gallagher, S., 2014. Depositional and diagenetic controls on reservoir heterogeneity: upper Morrow Sandstone, Farnsworth Unit, Ochiltree County,Texas. In: M.S. Thesis. New Mexico Institute of Mining and Technology.

Gershenzon, N.I., Soltanian, M.R., Ritzi, R.W., Dominic, D.F., 2014. Understandingthe impact of open-framework conglomerates on water-oil displacements:victor interval of the Ivishak Reservoir, Prudhoe Bay Field, Alaska. Pet. Geosci. 21, 43-54.

Gershenzon, N.I., Soltanian, M.R., Ritzi, R.W., Dominic, D., Mehnert, E., Okwen, R.,2015a. Influence of small-scale, fluvial, sedimentary architecture on $\mathrm{CO}_{2}$ trapping processes in deep brine reservoirs. Water Resour. Res. 15 (10), 8240-8256.

Gershenzon, N.I., Soltanian, M.R., Ritzi, R.W., Dominic, D., Keefer, D., Shaffer, E.,Storsved, B., 2015b. How does the connectivity of open-framework conglomerates within multi-scale hierarchical fluvial architecture affect oilsweep efficiency in waterflooding? Geosphere. 11(6), 2049-2066.

Hosseini, S.A., Lashgari, H., Choi, J.W., Nicot, J.P., Lu, J. and Hovorka, S.D., 2013. Static and dynamic reservoir modeling for geological $\mathrm{CO}_{2}$ sequestration at Cranfield, Mississippi, USA. Int. J. Greenh. Gas Control. 18, 449-462.

Holloway, S., 2005. Underground sequestration of carbon dioxide-a viable greenhouse gas mitigation option. Energy. 30(11), 2318-2333.

Hovorka, S.D., Meckel, T.A., Trevino, R.H., Lu, J., Nicot, J.P., Choi, J.W., Freeman, D., Cook, P., Daley, T.M., Ajo-Franklin, J.B. and Freifeild, B.M., 2011. Monitoring a large volume $\mathrm{CO}_{2}$ injection: year two results from SECARB project at Denbury's Cranfield, Mississippi, USA. Energy Procedia. 4, 3478-3485.

Hovorka, S.D., Meckel, T.A. and Trevino, R.H., 2013. Monitoring a large-volume injection at Cranfield, Mississippi-Project design and recommendations. Int. J. Greenh. Gas Control. 18, 345-360.

Hoteit, H. and Firoozabadi, A., 2006. Compositional modeling by the combined discontinuous Galerkin and mixed methods. SPE J. 11(01), pp.19-34.

Iglauer, S., Pentland, C.H. and Busch, A., 2015. $\mathrm{CO}_{2}$ wettability of seal and reservoir rocks and the implications for carbon geo-sequestration. Water Resour. Res. 51(1), 729-774.

Kharaka, Y.K., Cole, D.R., Hovorka, S.D., Gunter, W.D., Knauss, K.G. and Freifeld, B.M., 2006. Gas-water-rock interactions in Frio Formation following $\mathrm{CO}_{2}$ injection: 
Implications for the storage of greenhouse gases in sedimentary basins. Geology, 34(7), 577-580.

Krevor, S., Pini, R., Zuo, L. and Benson, S.M., 2012. Relative permeability and trapping of $\mathrm{CO}_{2}$ and water in sandstone rocks at reservoir conditions. Water Resour. Res. 48(2).

Lake, L.W., 2010. Enhanced Oil Recovery. Society of Petroleum Engineers (Reprint), Richardson, Texas.

$\mathrm{Li}, \mathrm{Z}$. and Firoozabadi, A., 2009. Cubic- plus- association equation of state for watercontaining mixtures: Is "cross association" necessary?. AlChE J. 55(7), 1803-1813.

Li, Z. and Firoozabadi, A., 2012. General strategy for stability testing and phase-split calculation in two and three phases. SPE J. 17(04), 1-096.

Lemmon, E.W., McLinden, M.O., Friend, D.G., 2005. In: Linstrom, P.J., Mallard, W.G. (Eds.), Thermophysical Properties of Fluid Systems in NIST Chemistry WebBook, NIST Standard Reference Database Number 69. National Institute of Standards and Technology, Gaithersburg, MD, 20899 http://webbook.nist.gov.

Leverett, M.C., 1941. Capillary behavior in porous solids. Transactions of the AIME $.142,159-172$.

Levine, J., 2011. Relative permeability experiments of carbon dioxide displacing brine \& their implications for carbon sequestration. In: PhD Dissertation. Columbia University.

Levine, J.S., Goldberg, D.S., Lackner, K.S., Matter, J.M., Supp, M.G., Ramakrishnan, T.S., 2014. Relative permeability experiments of carbon dioxide displacing brine and their implications for carbon sequestration. Environ. Sci. Technol. 48 (1), 811-818.

Lu, J., Cook, P.J., Hosseini, S.A., Yang, C., Romanak, K.D., Zhang, T., Freifeld, B.M., Smyth, R.C., Zeng, H., Hovorka, S.D., 2012a. Complex fluid flow revealed by monitoring $\mathrm{CO}_{2}$ injection in a fluvial formation. J. Geophys. Res. 117, B03208.

Lu, J., Kharaka, Y.K., Thordsen, J.J., Horita, J., et al., 2012b. CO2-rockbrine interactions in Lower Tuscaloosa Formation at Cranfield $\mathrm{CO}_{2}$ sequestration site, Mississippi, U.S.A. Chem Geol. 291, 269-277.

McGuire, P.L., and Stalkup, F.I., 1995. Performance analysis and optimization of the Prudhoe Bay miscible gas project. SPE Reservoir Eng. 10, 88-93.

McGuire, P.L., Spence, A.P., Stalkup, F.I. and Cooley, M.W. 1995. Core acquisition and analysis for optimization of the Prudhoe Bay miscible-gas project. SPE Reservoir Eng. 10, 94-100.

Mito, S., Xue, Z. and Ohsumi, T., 2008. Case study of geochemical reactions at the 
Nagaoka $\mathrm{CO}_{2}$ injection site, Japan. Int. J. Greenh. Gas Control. 2(3), 309-318.

Moortgat, J., Li, Z. and Firoozabadi, A., 2012. Three- phase compositional modeling of $\mathrm{CO}_{2}$ injection by higher- order finite element methods with CPA equation of state for aqueous phase. Water Resour. Res. 48(12).

Moortgat, J. and Firoozabadi, A., 2013. Fickian diffusion in discrete-fractured media from chemical potential gradients and comparison to experiment. Energy Fuels, 27(10), 5793-5805.

Moortgat, J.B. and Firoozabadi, A., 2013. Three-phase compositional modeling with capillarity in heterogeneous and fractured media. SPE J. 18(06),1-150.

Moortgat, J., Sun, S., Firoozabadi, A., 2011. Compositional modeling of three- phase flow with gravity using higher-order finite element methods. Water Resour. Res. 47 (5).

Moortgat, J. and Firoozabadi, A., 2010. Higher-order compositional modeling with Fickian diffusion in unstructured and anisotropic media. Adv. Water Resour. 33(9), 951968.

Moortgat, J. and Firoozabadi, A., 2016. Water Coning, Water and $\mathrm{CO}_{2}$ Injection in Heavy Oil Fractured Reservoirs. SPE Reserv. Eval. Eng., SPE-183648-PA.

Moortgat, J., 2016. Viscous and gravitational fingering in multiphase compositional and compressible flow. Adv. Water Resour. 89, 53-66.

Mukhopadhyay, S., Birkholzer, J.T., Nicot, J.P. and Hosseini, S.A., 2012. A model comparison initiative for a $\mathrm{CO}_{2}$ injection field test: an introduction to Sim-SEQ. Environ. Earth Sci. 67(2), 601-611.

Mukhopadhyay, S., Doughty, C., Bacon, D., Li, J., Wei, L., Yamamoto, H., Gasda, S., Hosseini, S.A., Nicot, J.P. and Birkholzer, J.T., 2015. The Sim-SEQ Project: Comparison of selected flow models for the S-3 Site. Transport Porous Med. 108(1), 207-231.

Pan, F., McPherson, B.J., Dai, Z., Jia, W., Lee, S.Y., Ampomah, W., Viswanathan, H. and Esser, R., 2016. Uncertainty analysis of carbon sequestration in an active $\mathrm{CO}_{2}-$ EOR field. Int. J. Greenh. Gas Control. 51, 18-28.

Pope, G.A., 1980. The application of fractional flow theory to enhanced oil recovery. SPE J., 20(03), 191-205.

Ritzi, R. W., Freiburg, J. T., \& Webb, N. D., 2016. Understanding the (co) variance in petrophysical properties of $\mathrm{CO}_{2}$ reservoirs comprising sedimentary architecture. Int. J. Greenh. Gas Control. 51, 423-434. 
Snedden, J. W., Vrolijk, P. J., Sumpter, L. T., Sweet, M. L., Barnes, K. R., White, E., Farrell, M. E., 2007. Reservoir connectivity: Definitions, examples and strategies, Soc. Petrol. Eng. Pap., 11375, 7 pp.

Sneider, R. M., Tinker, C. N., and Meckel, L. D. 1978. Deltaic environment reservoir types and their characteristics. JPT J. Pet. Technol. 30,1538-1546, doi:10.2118/6701PA.

Stone, H., 1970. Probability model for estimating three-phase relative permeability, J. Petrol. Technol. 22(2), 214-218.

Stone, H., 1973. Estimation of three-phase relative permeability and residual oil data, J. Can. Petrol. Technol. 12, 53-61.

Shahraeeni, E., Moortgat, J., \& Firoozabadi, A., 2015. High-resolution finite element methods for 3D simulation of compositionally triggered instabilities in porous media. Comput. Geosci. 19(4), 899-920.

Schrag, D.P., 2007. Preparing to capture carbon, Science. 315, 812-813, doi:10.1126/science.1137632.

Sun, A.Y., Lu, J., Freifeld, B.M., Hovorka, S.D. and Islam, A., 2016. Using pulse testing for leakage detection in carbon storage reservoirs: A field demonstration. Int. J. Greenh. Gas Control. 46, 215-227.

Tye, R.S., Watson, B.A., McGuire, P.L., Maguire, M.M., 2003. Unique horizontalwelldesigns boost primary and EOR production, Prudhoe Bay field, Alaska. In:

Carr, T.R., Mason, E.P., Feazel, C.T., (Eds.), Horizontal wells: Focus on the reservoir. AAPG Methods in Exploration. 14,113-125.

Vasco, D. W., A. Rucci, A. Ferretti, F. Novali, R. C. Bissell, P. S. Ringrose, A. S. Mathieson, and I. W. Wright, 2010. Satellite-based measurements of surface deformation reveal fluid flow associated with the geological storage of carbon dioxide, Geophys. Res. Lett. 37, L03303, doi:10.1029/2009GL041544.

Weaver, L.K., Anderson, K.F., 1966. Cranfield Field, Cranfield Unit, Basal Tuscaloosa Reservoir, Adams and Franklin Counties, Mississippi, in Oil Recovery from Gas-Cap Reservoirs: An Engineering Evaluation of Conservation Practices in Six Reservoirs. Interstate Oil Compact Commission, Oklahoma City, 42-58.

Willis, B. J., and C. D. White, 2000. Quantitative outcrop data for flow simulation, J. Sediment. Res. 70, 788-802.

Yoshida, N., Levine, J. S., \& Stauffer, P. H., 2016. Investigation of uncertainty in $\mathrm{CO}_{2}$ reservoir models: A sensitivity analysis of relative permeability parameter values. Int. J. Greenh. Gas Control. 49, 161-178. 